\title{
Active surveillance of small renal masses
}

\author{
Carmen Sebastià ${ }^{1}$, Daniel Corominas ${ }^{1 *}$, Mireia Musquera $^{2}$, Blanca Paño ${ }^{1}$, Tarek Ajami $^{2}$ and Carlos Nicolau ${ }^{1}$
}

\begin{abstract}
Most renal masses incidentally detected by cross-sectional images are benign, being mainly cysts, and if they are malignant, they are indolent in nature with limited metastatic potential. Enhanced renal masses less than $4 \mathrm{~cm}$ in size are known as small renal masses (SRMs), and their growth rate (GR) and the possibility of developing metastasis are extremely low. Delayed intervention of SRMs by closed and routine imaging followup known as active surveillance (AS) is now an option according to urological guidelines. Radiologists have a key position in AS management of SRMs even unifocal and multifocal (sporadic or associated with genetic syndromes) and also in the follow-up of complex renal cysts by Bosniak cyst classification system. Radiologists play a key role in the AS of both unifocal and multifocal (sporadic or associated with genetic syndromes) SRMs as well as in the follow-up of complex renal cysts using the Bosniak cyst classification system. Indeed, radiologists must determine which patients with SRMs or complex renal cysts can be included in AS, establish the follow-up radiological test algorithm to be used in different scenarios, perform measurements in follow-up tests, and decide when AS should be discontinued. The purpose of this article is to review the indications and management of AS in SRMs, especially focused on specific scenarios, such as complex renal cysts and multifocal renal tumors (sporadic or hereditary). In this work, the authors aimed to provide a thorough review of imaging in the context of active surveillance of renal masses.
\end{abstract}

Keywords: Small renal mass, Renal cell carcinoma, Elderly, Diagnostic imaging, Delayed intervention

\section{Key points}

- Small renal masses are contrast-enhancing renal tumors less than or equal to $4 \mathrm{~cm}$.

- Active surveillance is defined as initial management including the monitoring of renal tumor size.

- The follow-up protocol most commonly used includes enhanced abdominopelvic CT scanning.

- Progression is defined as a linear growth rate greater than $0.5 \mathrm{~cm}$ per year, diameter greater than $4 \mathrm{~cm}$, or metastasis.

\footnotetext{
* Correspondence: dcorominas@clinic.cat

${ }^{1}$ Radiology Department, CDIC, Hospital Clínic de Barcelona, CNillaroel no. 170, 08036 Barcelona, Spain

Full list of author information is available at the end of the article
}

\section{Background}

Over the last 20 years, the incidence of renal cell carcinoma (RCC) has increased globally due to advances in cross-sectional imaging of small renal masses (SRMs). SRMs are defined as incidentally image-detected, contrast-enhancing renal tumors less than or equal to $4 \mathrm{~cm}$ in diameter which are usually consistent with stage T1a renal cell carcinoma [1]. Adequate clinical management of SRMs is important despite their slow growth and rare metastatic potential. Optimal management of SRMs should balance the need for treatment, as around 25\% of all small masses are benign lesions, with the goal of preserving renal function as far as possible and avoiding the risk of overtreatment [2]. An important proportion of SRMs are diagnosed in older patients or patients with multiple comorbidities, in whom surgery might outweigh the potential clinical benefits of active 


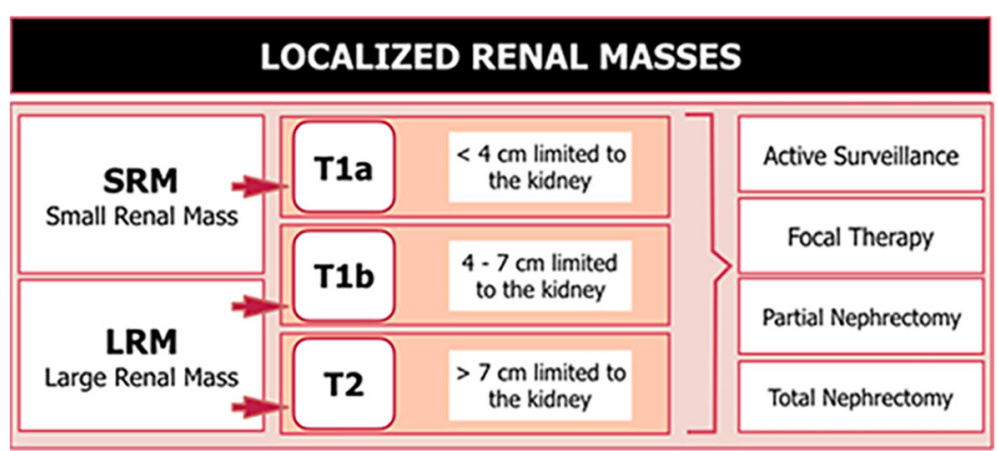

Fig. 1 Definition, classification, and therapeutic approaches of localized renal masses. Localized renal masses were considered to be all the masses limited to the kidney which means no perinephric or renal sinus fat invasion. T1a, T1b, and T2 correspond to the TNM classification

surveillance (AS). Active surveillance is defined as the initial management including the monitoring of renal tumor size by serial imaging with delayed treatment in case of progression and is now considered as an option in the treatment of localized renal tumors [3] (Fig. 1). Nonetheless, AS should be differentiated from the watchful waiting (WW) approach in which patient monitoring with imaging techniques is not routine, curative treatment is not administered and active treatment is not indicated unless symptoms appear [4] (Fig. 2).

The aim of this review is to describe the indications and practical management of AS in SRMs, especially focused on specific scenarios such as complicated renal cysts and multifocal renal tumors (sporadic or hereditary).

\section{Renal masses: indications for active surveillance}

Small renal masses are the ones most indicated to be included in AS. Since SRMs tend to be indolent, with slow growth rates (1-3 mm per year), and are associated with a relatively low risk of metastasis (1-3\%). AS is the most adequate treatment approach [5-7]. Large renal masses (LRM), which are defined as solid localized renal masses greater than $4 \mathrm{~cm}$ in size usually corresponding to $\mathrm{T} 1 \mathrm{~b}$ and T2 RCC, can also be followed by AS, although the more rapid growth (4-8 $\mathrm{mm}$ per year) and higher risk of M1 metastasis (4-6\%) require that this approach be made with caution [8].

In the absence of level I evidence, the criteria for patients with SRMs to be eligible to receive AS are difficult to define. In various urologic guidelines, AS is considered to be a treatment option in elderly

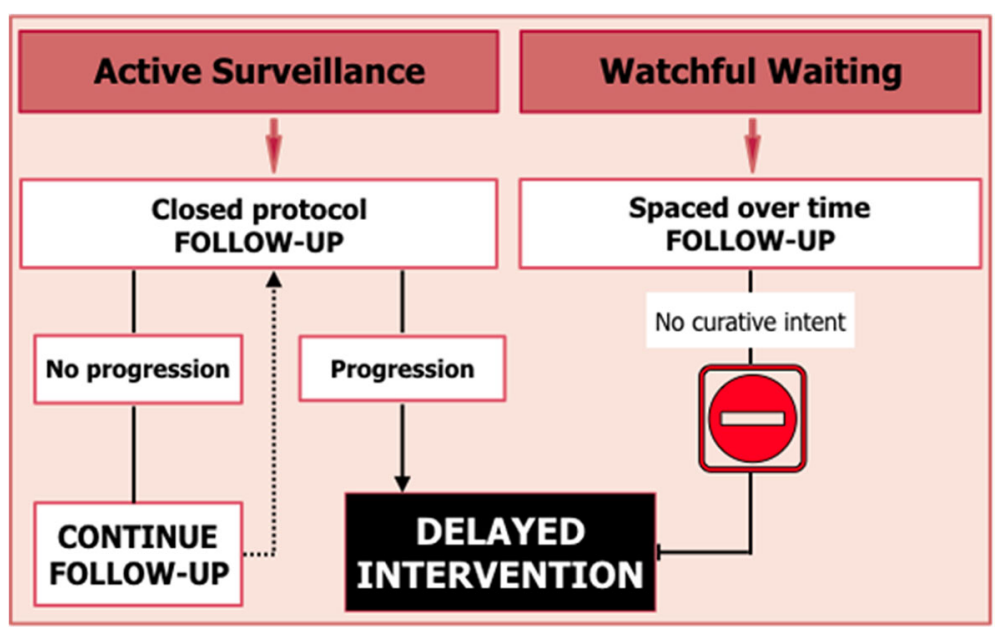

Fig. 2 The main differences between active surveillance (AS) and watchful waiting (WW) in the monitoring of small renal masses. Active surveillance is defined as the initial management including the monitoring of renal tumor size by serial imaging with delayed treatment in case of progression. In WW, close monitoring with imaging techniques is not routine, curative treatment is not administered, and active treatment is only indicated on the appearance of symptoms 
patients (although none defines a specific cutoff age), as well as in patients with multiple comorbidities and a limited life expectancy or with high perioperative morbid-mortality risk [2, 4, 9-11]. AS is also considered in chronic kidney disease or individual kidney patients in whom an observation period can be considered [12]. Only the recent American Urology Association (AUA) and the American Society of Clinical Oncology (ASCO) guidelines for SRMs provide an indepth description of the indications of AS [2-4].
According to the 2017 AUA guidelines [4]:

- AS is an option for initial management in patients with renal masses suspicious for cancer, especially those smaller than $2 \mathrm{~cm}$.

- AS or expectant management should be a priority when the anticipated risk of intervention or competing risks of death outweigh the potential oncologic benefits of active treatment.
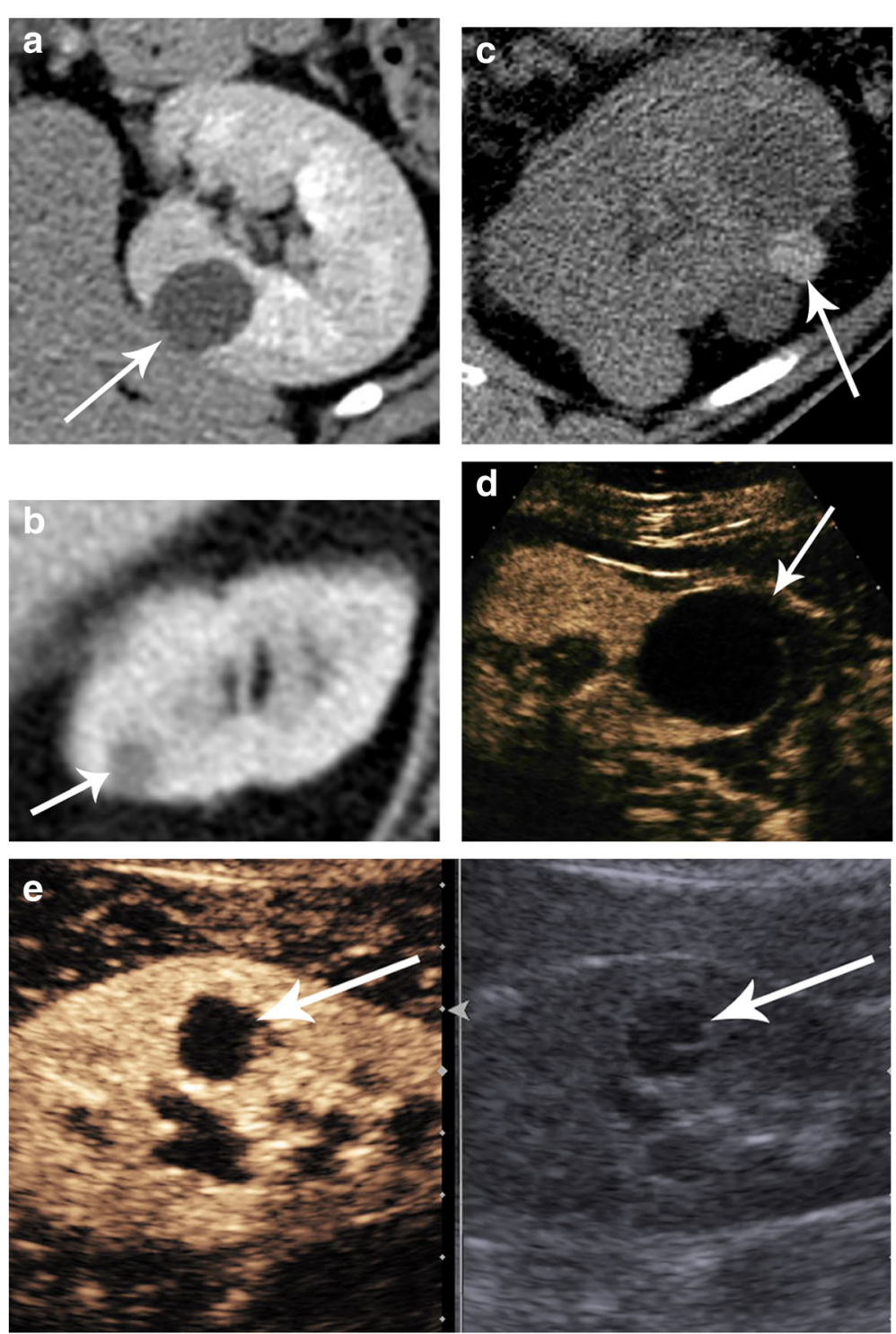

Fig. 3 Renal masses that do not need to be followed. a Axial contrast-enhanced CT showing a right renal too small to characterize mass (TSTC) (arrow); the renal mass is $8 \mathrm{~mm}$ in size, and the CT slice thickness is $5 \mathrm{~mm}$, making the renal mass size less than twice the reconstructed CT thickness $(8 \mathrm{~mm} / 10 \mathrm{~mm})$. b Axial contrast-enhanced CT showing a hypodense left kidney lesion measuring $3 \mathrm{HU}$ (less than $20 \mathrm{HU}$ ), which is likely a simple cyst (arrow). c Axial non-enhanced CT showing a hyperdense left kidney cyst with an attenuation value of $85 \mathrm{HU}$ greater than $70 \mathrm{HU}$, consistent with a hemorrhagic cyst (arrow). d Contrast-enhanced US of a Bosniak I cystic lesion showing no wall thickening or septa (arrow). e Unenhanced (right) and contrast-enhanced (left) US of a renal Bosniak II cystic lesion with thin septa that did not enhance in the post-contrast study (arrows) 

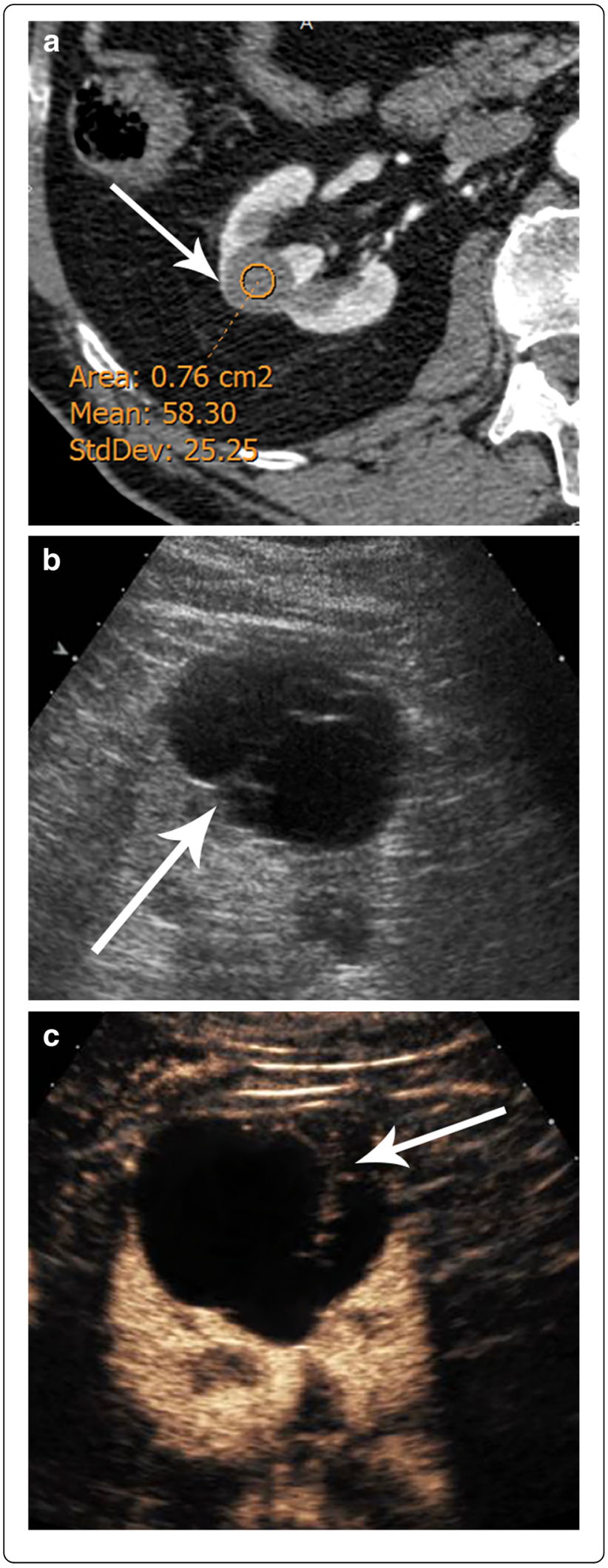

Fig. 4 Indeterminate renal mass by $C T$ in the right kidney. a Axial CT in the arterial phase depicts a renal tumor with $58 \mathrm{HU}$ consistent with the indeterminate lesion (arrow). b Unenhanced and (c) contrast-enhanced ultrasound (US) of the same renal tumor showing the presence of a cyst with thin septa with no contrast uptake corresponding to a Bosniak II lesion (arrow): follow-up was not required

- When the results of a risk-versus-benefit analysis of the treatment are equivocal and the patient elects to undergo AS.

- When the oncologic benefits of intervention outweigh the risks of treatment and competing risks of death, physicians should recommend active treatment. In this setting AS with potential for delayed intervention may be pursued only if the patient understands and is willing to accept the associated oncologic risk.

The ASCO guidelines define the indications of AS as follows [2]:

- Absolute indications: high risk for anesthesia and intervention or life expectancy less than 5 years

- Relative indications: significant risk of end-stage renal disease (ESRD) if treated, SRM less than $1 \mathrm{~cm}$, or life expectancy less than 10 years

In clinical practice, the indication of AS is evaluated individually by tumor boards, with the risk of RCC treatment being balanced with the oncologic results of AS, patient age, comorbidities, and limited life expectancy, and finally, leading to multidisciplinary consensus.

\section{Renal masses: contraindications for active surveillance}

AS should not be carried out in the following:

- Benign renal masses reliably diagnosed by imaging or biopsy

- Renal masses with irregular borders

- Non-localized renal tumors (i.e., locally, lymphatically, or hematogenously disseminated)

- When the oncologic benefits of intervention outweigh the risks of treatment and competing risks of death

- When the patient refuses to be included in AS

Most renal masses incidentally found by crosssectional imaging are cysts which, according to the Bosniak renal cyst classification system, do not require follow-up [13]. In 2017, the Incidental Findings Committee (IFC) of the American College of 
Radiology (ACR) updated its recommendations on the management of incidental renal masses by computed tomography (CT) [14]. This excellent guideline describes the different scenarios of the management of incidental renal masses. It is of note that in these guidelines, the following renal masses presumed to be non-complicated cysts and considered benign by imaging techniques do not require follow-up or treatment (Fig. 3).

- Homogeneous well-defined, too small to be characterized renal masses (TSTC) supposed to be cysts. Too small to characterize renal masses occur when the lesion size is less than twice the reconstructed slice thickness (Fig. 3a).

- Homogeneous well-defined renal masses with attenuation -10 to 20 Hounsfield units (HU) by CT are likely benign cysts (Fig. 3b).

- Homogeneous well-defined renal masses with attenuation $\geq 70 \mathrm{HU}$ on non-contrast CT consistent with hemorrhagic cysts (Fig. 3c).

- Completely characterized Bosniak I cysts diagnosed by ultrasound (US), CT, or magnetic resonance imaging (MRI) (Fig. 3d).

- Completely characterized Bosniak II cysts diagnosed by US, CT, or MRI (Fig. 3e).
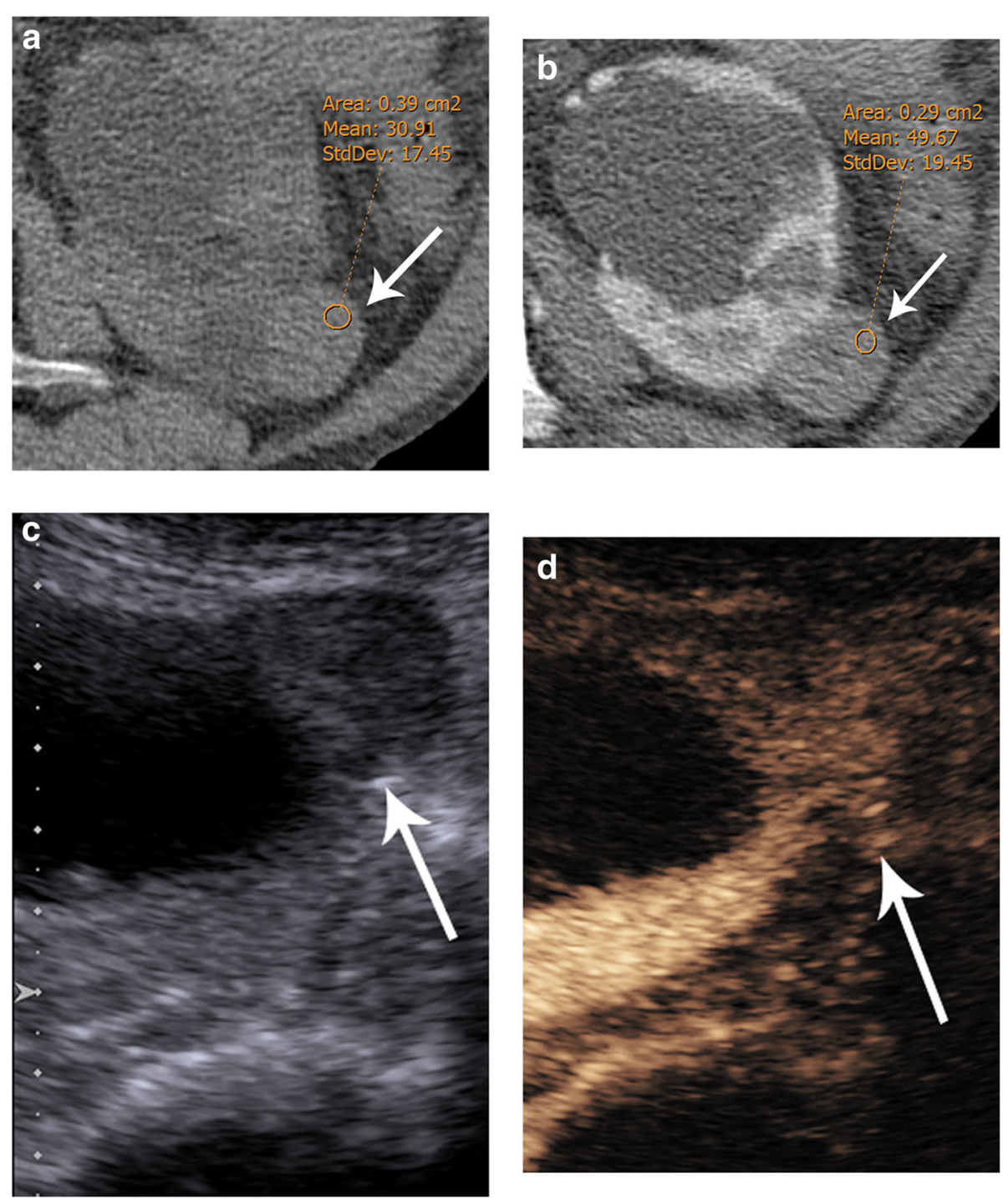

Fig. 5 Indeterminate renal mass by CT in an 82-year-old patient. a Axial unenhanced and (b) enhanced CT showing a renal mass with attenuation greater than $20 \mathrm{HU}$ in unenhanced CT that enhances less than $20 \mathrm{HU}$ after contrast administration, considered indeterminate by $\mathrm{CT}$ (arrows). c Unenhanced and (d) contrast-enhanced ultrasound (US) of the same lesion clearly depicting enhancement of this lesion consistent with a solid renal tumor (arrows), thereby allowing an indeterminate CT renal mass to be reliably classified as a solid mass 


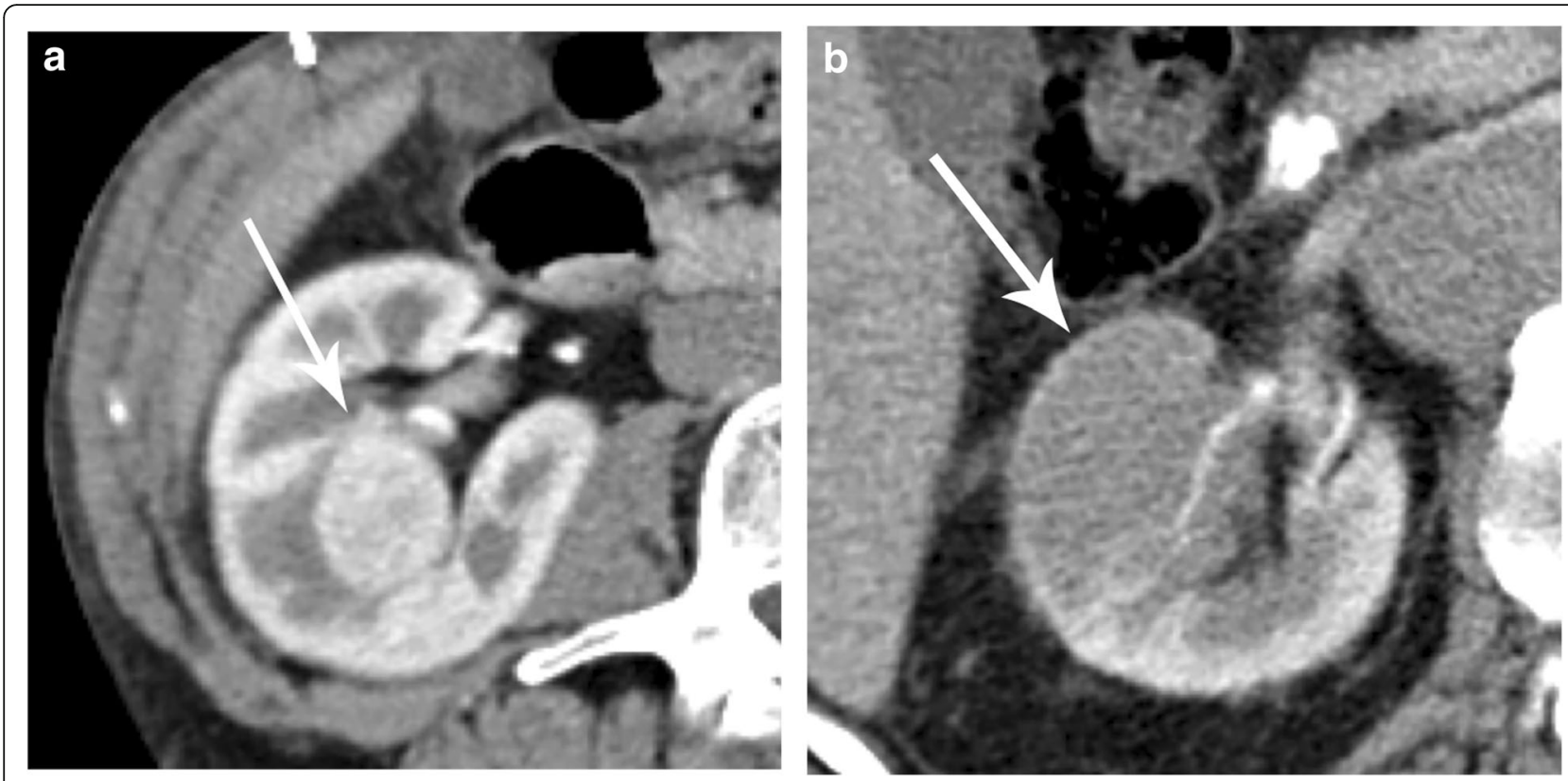

Fig. 6 Solid renal masses in two elderly patients with regular and irregular borders. a Axial contrast-enhanced CT in the arterial phase shows a hyperdense right renal mass with smooth margins and regular shape (arrow) which, if indicated, can be managed with active surveillance. $\mathbf{b}$ Axial contrast-enhanced CT scan in the nephrographic phase depicting a hypodense renal mass with irregular borders (arrow). Active surveillance is not indicated in this case

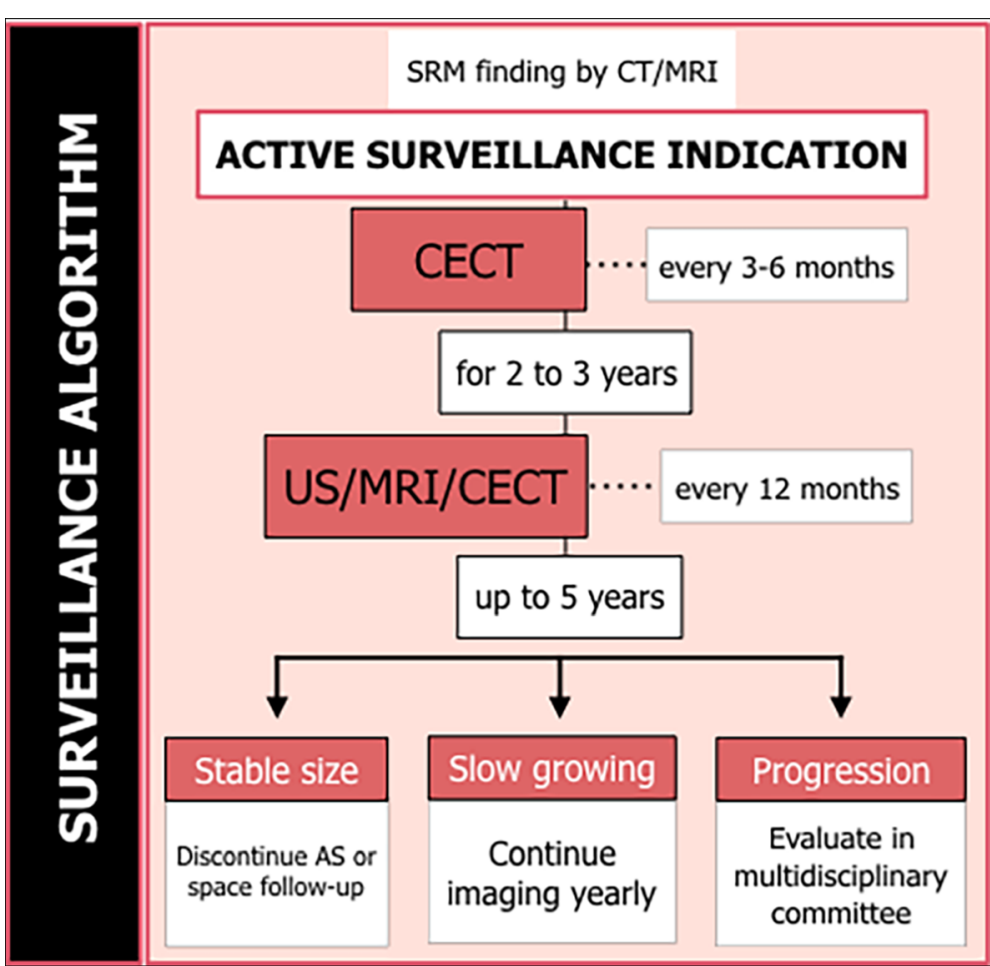

Fig. 7 Suggested active surveillance management algorithm. Contrast-enhanced computerized tomography (CECT), ultrasound (US), and magnetic resonance (MR) 

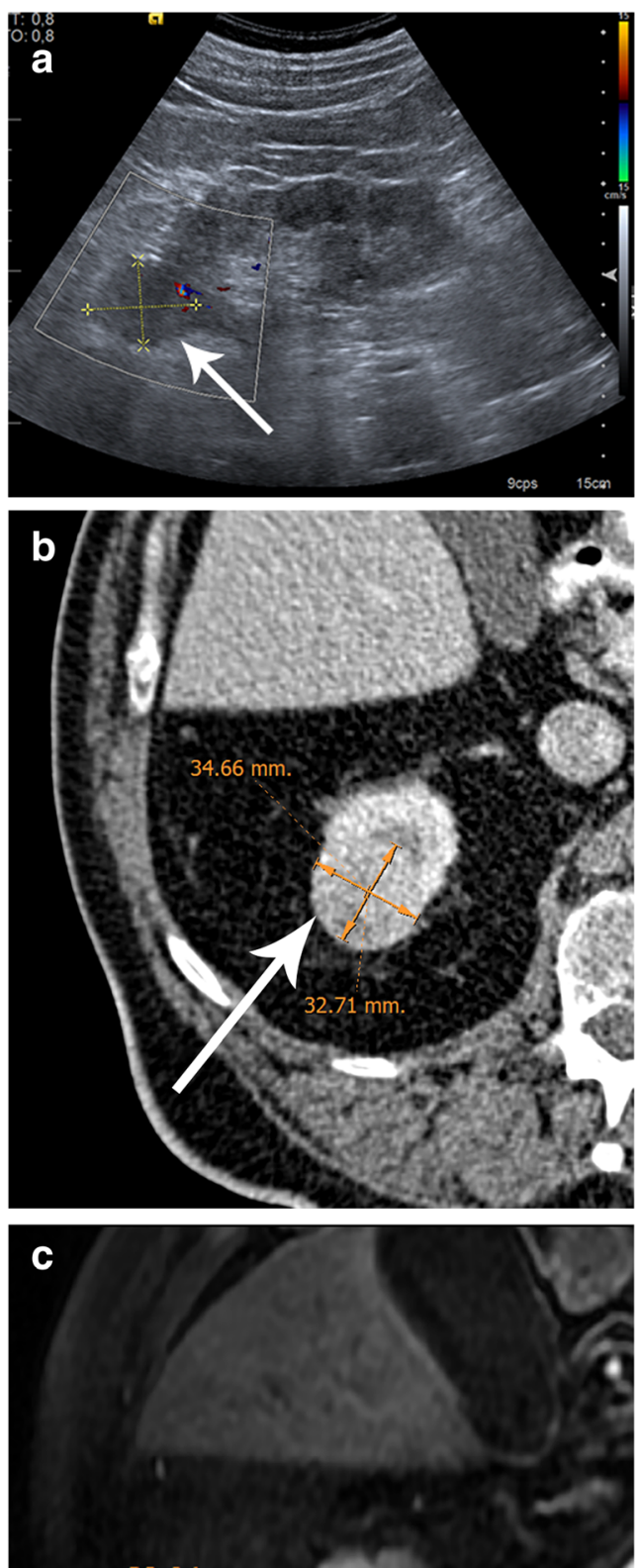

$32.94 \mathrm{~mm}$

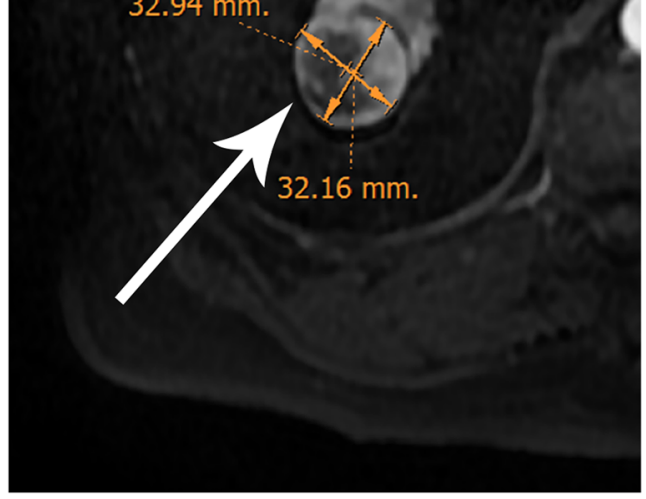

Fig. 8 Comparison of maximum tumor diameter (MTD) in the axial plane of a small renal mass (SRM) with different imaging modalities (arrows). a Sagittal ultrasound (US) view. b Axial contrast-enhanced $C T$ scan and (c) axial contrast-enhanced T1-weighted MR of the same renal lesion demonstrating there are no significant differences between US, CT, and MR with the use of the same plane for measuring MTD $(3.33 \mathrm{~cm}, 3.46 \mathrm{~cm}$, and $3.29 \mathrm{~cm}$, respectively). Note that the differences between different radiological tests are less than $0.2 \mathrm{~cm}$

The use of contrast-enhanced ultrasound (CEUS) can help to differentiate benign renal lesions and thereby increase the number of lesions that do not need to be followed. In our clinical practice, usually, we face only an enhanced $\mathrm{CT}$ with a renal mass measuring more than $20 \mathrm{HU}$, which is considered indeterminate. CEUS plays an important role in converting these indeterminate CT lesions into benign Bosniak I/II cysts that do not require further examination [15-17] (Fig. 4). On the other hand, some lowgrade RCCs, especially the papillary subtype, show very slight enhancement which may not be clearly detected by CT or MR [18]. CEUS has shown to be an excellent tool in demonstrating blood flow within these hypovascular tumors (Fig. 5).

AS is indicated only in SRMs which are regular in shape since masses with irregular borders are highly suspicious of being an aggressive tumor (Fig. 6). Renal masses with fat attenuation areas by CT or MR (macroscopic renal fat) without associated calcification are consistent with angiomyolipomas and must be managed separately and not by AS [14].

Localized renal masses mean that the tumor is contained by the capsule, independently of the size. If the tumor invades the capsule, the sinus, the renal vein, and the perirenal fat or has positive lymphatic or hematogenous spread, it is not considered a localized tumor, and AS is not an option [19].

\section{When to perform a biopsy in AS}

In order to differentiate between benign and malignant tumors in the setting of incidental renal masses, radiological characteristics can be crucial. In this setting, many studies are focused on radiologic findings trying to correlate them with histological classifications. Currently, radiologists can properly characterize cysts or fat tumors consistent with angiomyolipoma as mentioned previously, but other renal mass histology cannot be predicted with $100 \%$ accuracy [20-22].

A quarter of SRMs are benign renal cortical tumors, such as oncocytoma, metanephric adenoma, and angiomyolipoma. Another 25\% of these SRMs are indolent in nature with limited metastatic potential, 


\section{Lineal growth rate}

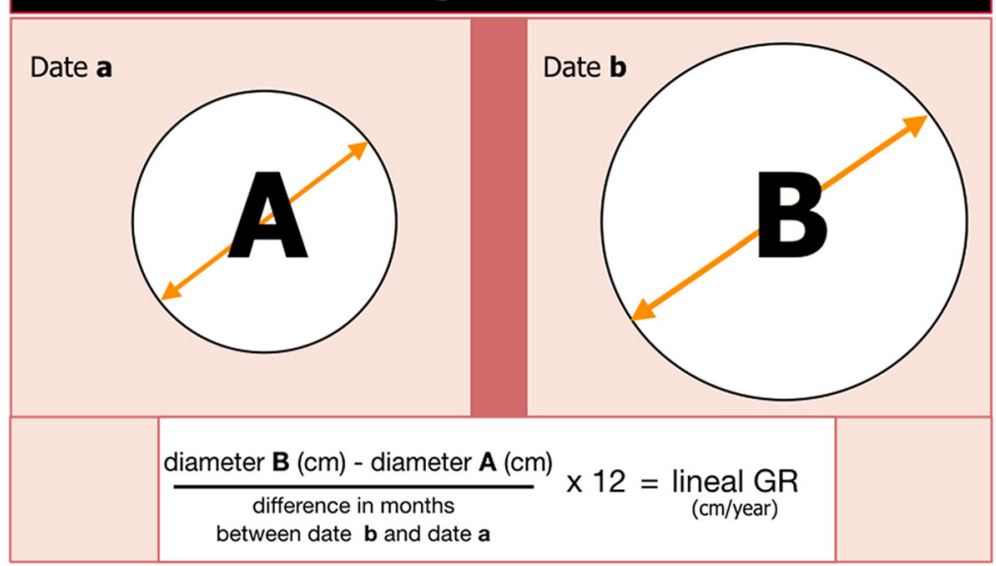

Fig. 9 Formula of linear growth rate (GR) per year. To define the linear GR per year, divide the difference between the maximum tumor diameter (MTD) into two time points by the difference of the number of months between the two CT times and then multiply by 12

including chromophobe, and type I papillary renal cancer [23]. Without histological assessment, the only parameter that helps to determine the aggressivity of these SRMs is their growth rate [24].

The prediction of biological tumor behavior plays an important role in choosing the most appropriate treatment in each case, AS being more adequate for benign and indolent renal tumors. All the current guidelines agree that renal tumor biopsy (RTB) should be performed, if clinically and technically possible, in cases in which the results might alter treatment [12]. According to the European Urology Association guidelines, RTB should only be performed before ablative or systemic therapy, while it is considered less necessary in AS (https://uroweb.org/guideline/renal-cell-carcinoma) [25].

As for the histological predictive factors of the biological behavior, the European urological guidelines include tumor grade, RCC subtype, sarcomatoid features, microvascular invasion, tumor necrosis, and invasion of the collecting system. Currently, there are some molecular factors described such as carbonic anhydrase IX (CaIX), VEGF, hypoxia-inducible factor (HIF), Ki67, p53, and $\mathrm{p} 21$, but none of these are routinely used [26].

Currently, RTB, and specifically core biopsy, is the only reliable way to confirm the diagnosis of renal masses without surgery. A recent systematic review summarizing RTB results reported a median overall diagnostic rate of $92 \%$ with a sensitivity and specificity of $99.7 \%$ and $93.2 \%$, respectively [23].

Although RTB may be helpful in achieving the diagnosis of renal tumors, in around 10 to $20 \%$ of the cases, this procedure is non-diagnostic. An oncocytic feature designation can be controversial because of the possibility of benign or malignant variant lesions. Moreover, tumor heterogenicity in terms of morphology, grade, and molecular characteristics is well recognized in renal tumors [27]. Nonetheless, two recent articles reported that the genetic heterogeneity of SRMs is not as great as previously thought [28, 29].

On the other hand, significant complications may occur in $5 \%$ of patients undergoing RTB, usually related to the development of perinephric hematomas. Seeding in the needle tract is in fact an extremely rare complication, with no cases described using the coaxial technique [30,31].

SRMs with irregular borders should be treated and should not be included in AS because of the high probability of aggressive malignancy. After having ruled out inflammatory and infectious masses, RTB should be performed to determine the possible presence of metastatic disease, urothelial carcinomas, and aggressive RCCs and lymphomas.

RTB is not performed in young or healthy patients, who are unwilling to accept the uncertainties associated with AS, or in older or frail patients who receive conservative treatment, independently of RTB findings [4].

\section{Active surveillance protocol}

When AS is determined to be the primary management option of a SRM, a strict follow-up imaging protocol must be carried out.

There is a consensus between guidelines as to the optimal imaging follow-up schedule. However, all guidelines agree that close follow-up is necessary during the first 2 to 3 years of AS, since most M1 appear during this 
period. In addition, the tumor growth rate (GR) is more undetermined in the first years [8].

The follow-up protocol most commonly used includes enhanced abdominopelvic CT scanning at 3-6-month intervals during the 2 or 3 first years and yearly thereafter. CT can be substituted by MR or US, especially after the 2 first years, to avoid radiation or in cases in which iodine contrast agents are contraindicated [12]. A complementary annual chest X-ray is also recommended in many guidelines [10] The surveillance algorithm of the National
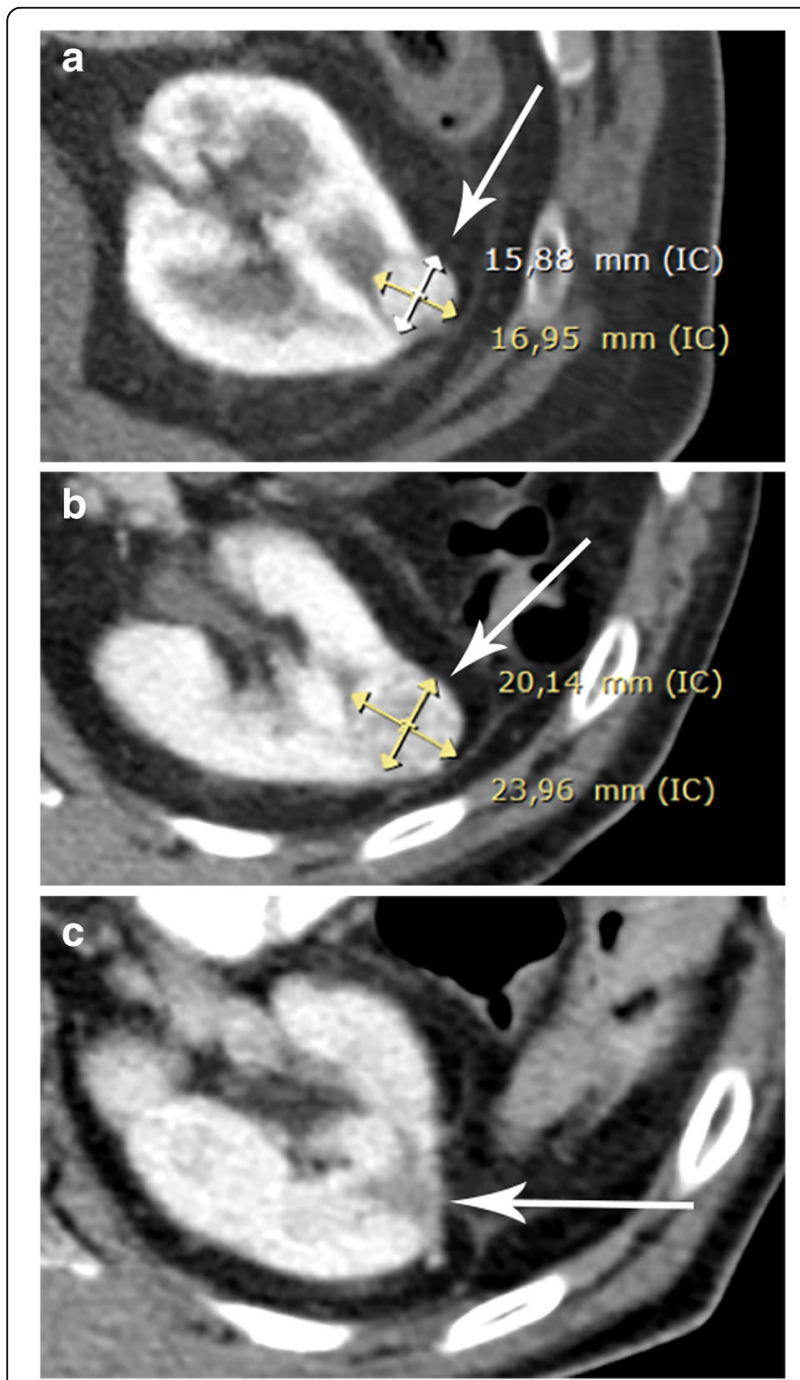

Fig. 10 Linear GR calculation of a SRM in AS in a 73-year-old patient. a Contrast-enhanced CT of a renal mass (arrow) with a MTD of $1.7 \mathrm{~cm}(16.95 \mathrm{~mm})$ at the beginning of AS and (b) 3 months later (arrow), showing a MTD of $2.4 \mathrm{~cm}(23.96 \mathrm{~mm})$. Using the linear GR formula, the difference of MTD $(2.4 \mathrm{~cm}-1.7 \mathrm{~cm}=0.7 \mathrm{~cm})$ is divided by the time between the two $C T$ scans ( 3 months), and the result $(0.3 \mathrm{~cm})$ is multiplied by 12 , resulting in $2.6 \mathrm{~cm}$. c Taking into account that the mass presented a GR of more than $0.5 \mathrm{~cm} / y e a r$, this mass should be considered as progressive, and AS should be discontinued. Following evaluation by a multidisciplinary committee, the patient underwent partial nephrectomy (arrow)
Comprehensive Cancer Network (NCCN) recommends the use of CT or MR of the head or spine in patients with SRM presenting neurologic symptoms or a bone scan in cases with elevated alkaline phosphatase values, bone pain, or abnormal radiologic findings [32]. A proposed followup AS algorithm is shown in Fig. 7.
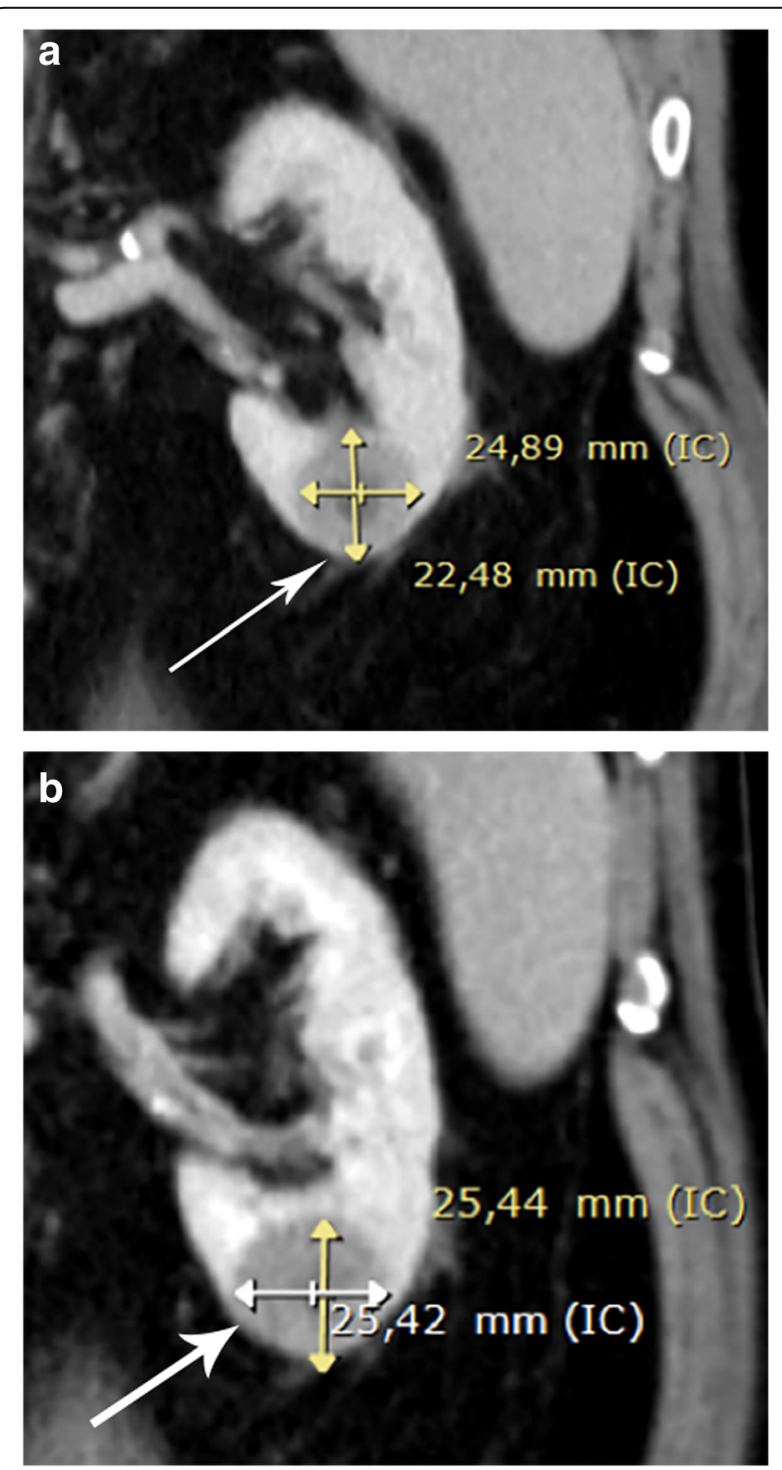

Fig. 11 Calculation of the linear growth rate (GR) of a lower third left kidney small renal mass (SRM) undergoing active surveillance (AS) in a 65-year-old patient (arrows). a Coronal contrast-enhanced CT of the renal mass showing an axial MTD of $2.5 \mathrm{~cm}(24.89 \mathrm{~mm})$ at the beginning of the surveillance and (b) 3 which had only increased to $2.5 \mathrm{~cm}$ (25.44) 3 years later. With the use of the linear GR formula in centimeters, $2.5 \mathrm{~cm}-2.5 \mathrm{~cm}=0 \mathrm{~cm}$ divided by 36 months and multiplied by 12 , the annual GR was shown to be $0 \mathrm{~cm} /$ year, indicating that the renal mass was stable. After 5 years of follow-up, the interval between imaging tests can be lengthened or even discontinued according to the decision of the multidisciplinary committee 


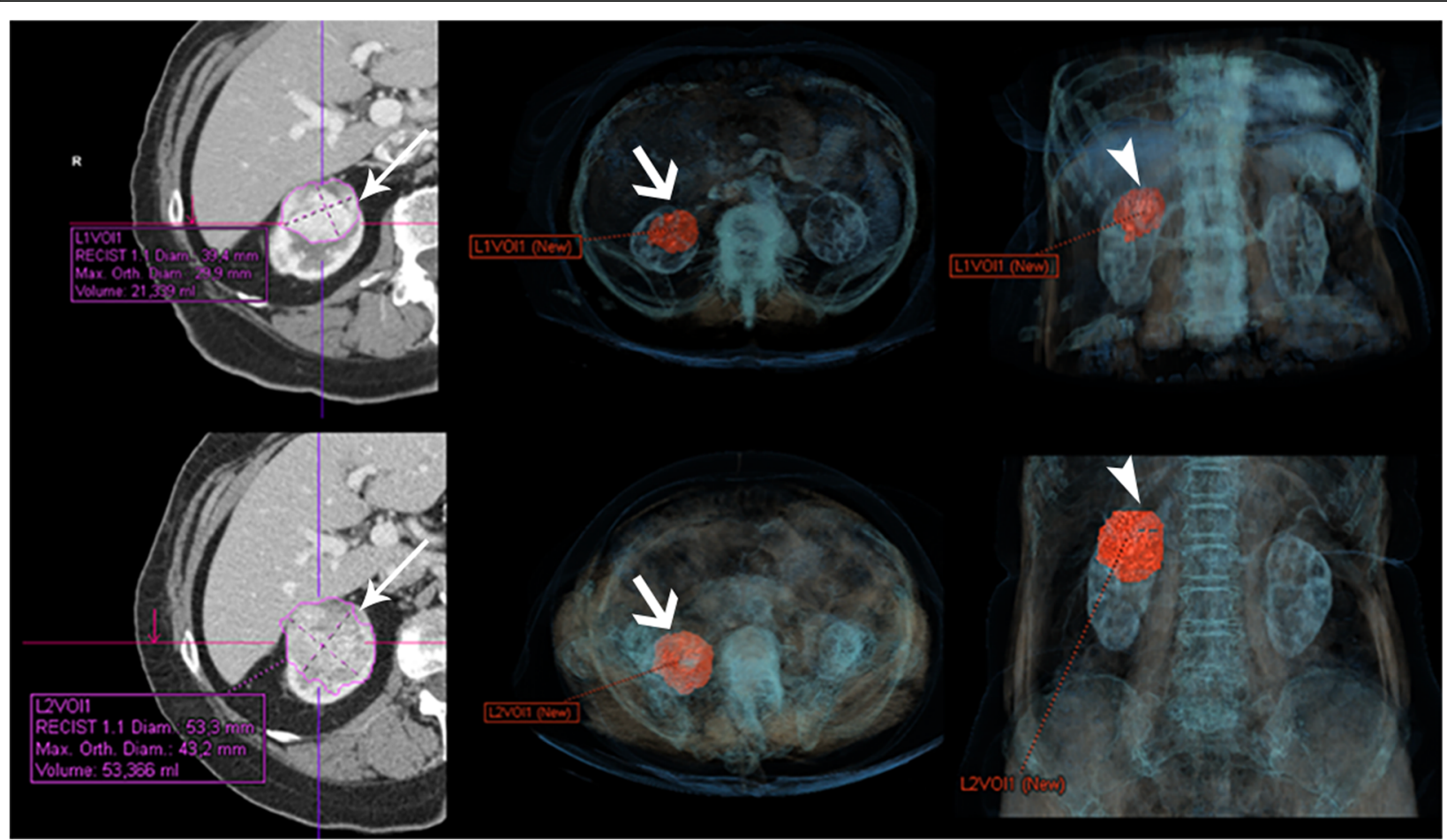

Fig. 12 Comparison between linear and volumetric measurements of small renal mass (SRM) growth over a 6-month period. Upper- and bottomleft: axial contrast-enhanced CT showing a renal mass with MTD $3.9 \mathrm{~cm}$ at the beginning of AS and $5.3 \mathrm{~cm}$ in the next study 6 months later with a linear GR of $1.4 \mathrm{~mm}$ between the two studies corresponding to a linear GR of $3.8 \mathrm{~cm} /$ year (arrows). Volumetric representation of the renal mass in an axial plane (thick arrows) (upper- and bottom-middle) and coronal plane (arrowheads) (upper- and bottom-right). The software showed an initial volume of $21 \mathrm{cc}$ and a final volume of $53 \mathrm{cc}$. The increase in volume was $32 \mathrm{cc}$, indicating that the mass had doubled in volume over a 6month period representing a rapid growth, although there are no established volume values to define progression

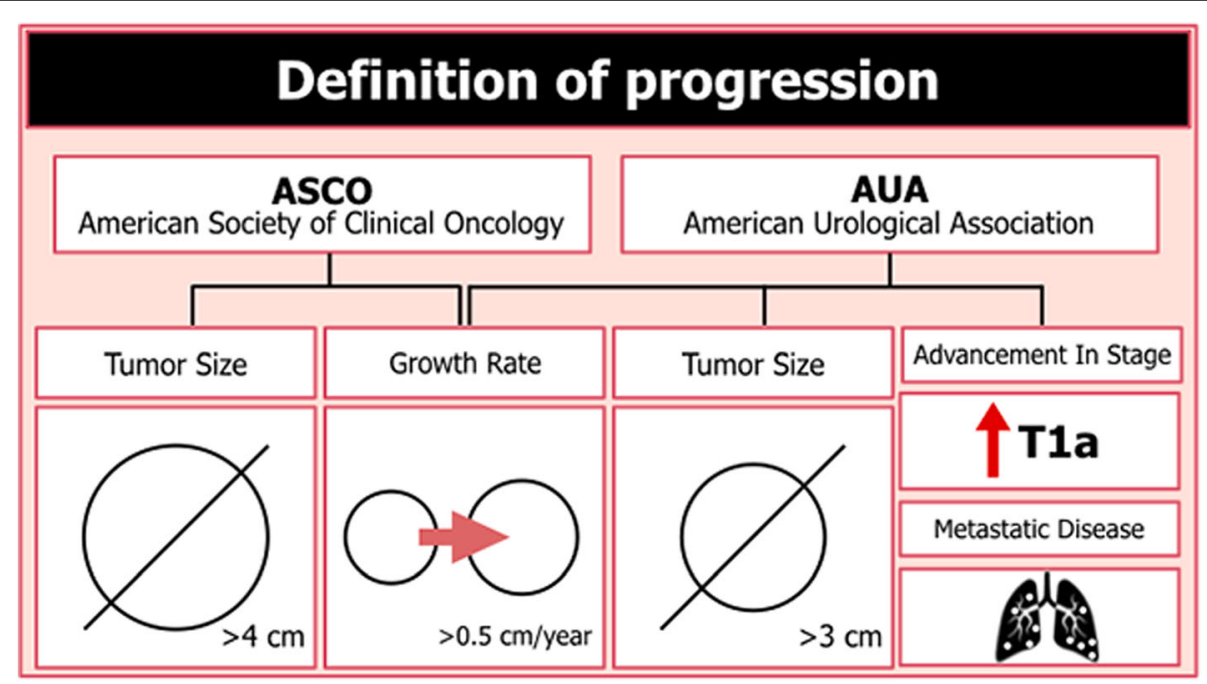

Fig. 13 Definition of active surveillance progression according to the American Society of Clinical Oncology (ASCO) and American Urological Association (AUA) guidelines 
In most of the studies comparing preoperative US, $\mathrm{CT}$, and MR results, the differences between the final kidney tumor size are minimal [33-36] (Fig. 8). The maximum tumor diameter (MTD) is the easiest way to measure SRMs, although the cross-sectional area and volume can also be measured. To define the linear GR, you divide the difference between MTD into two time points and the number of months passed and then multiply by 12 , to obtain the GR/year [37] (Fig. 9).

The linear GR is a universally available and easy AS method of SRMs. Several studies have shown the linear GR to have a good correlation with tumor aggressiveness to guide patient follow-up and be a potential determinant for intervention [38-42]. However, not all studies have shown an association between the tumor GR and the characteristics of high-risk tumors. The tumor GR alone is not a sufficient predictor of malignancy because benign masses can grow at a similar rate to that of malignant lesions $[37,43]$. Despite the ongoing debate of predictors of GR and tumor aggressiveness, the majority of the literature supports the concept that larger tumor size and a fast GR are associated with more aggressive disease. Therefore, it is currently recommended that tumor size greater than $4 \mathrm{~cm}$ and tumor growth of greater than $0.5 \mathrm{~cm} /$ year be used as a marker of disease progression and for establishing definitive treatment [44] (Fig. 10). Nonetheless, it must also be acknowledged that a proportion of masses display no growth or even regress in size. The proportion of SRMs with negative or zero growth ranges from 10 to $25 \%$ in different series [42, 45, 46] (Fig. 11), and in these cases, patient follow-up with imaging techniques can be less frequent (every 2-3 years) or even discontinued after 5 years of documented stability.

The slow relative GR of SRMs and the risk of intra- and interobserver variability require accurate radiographic measurement to establish subtle changes in mass dimension [47]. The use of mixed modalities of imaging such as US, CT, and MR is used in the follow-up of SRMs, measurement accuracy diminishes, although the differences between US, $\mathrm{MR}$, and CT results are only of $0.1-0.2 \mathrm{~mm}$ [48].

When a SRM is followed by AS, the same imaging modality should be used throughout the AS in order to avoid the variability in measurement between different techniques, at least during the first 2 to 3 years. Indeed, enhanced CT is recommended in these cases because of its reproducibility and higher spatial resolution. It is also important to measure the lesion on the same plane, in the same direction, and in the same slice, recommending the nephrographic phase to reduce variability. It is recommended to record the image with a size caliper and compare it from one test time to another, or report the slice and the sequence used for measurement using response evaluation criteria in solid tumor (RECIST) measurements.

Volumetric measurement is more accurate than axial diameters and can detect smaller growth. However, the reconstruction of these images requires more time as well as specific software which may not be available in all centers (Fig. 12).

AS should be discontinued on the progression of SRM, when the patient wishes active treatment or because of changes in the clinical situation. Progression is defined as linear GR greater than $0.5 \mathrm{~cm}$ per year, a tumor diameter greater than $4 \mathrm{~cm}$, or the development of metastasis (Fig. 13) [2, 4]. Patients undergoing AS can, at any time, decide to initiate active treatment or may also choose to remain on AS despite having progressed [45]. In stable SRMs, follow-up can be discontinued or lengthened after 5 years, although there is no consensus in urological or oncological guidelines regarding which cases and at what time follow-up can be safely discontinued.

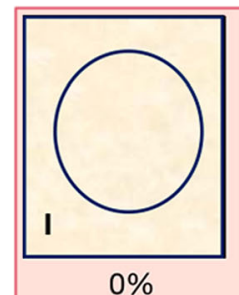

$0 \%$

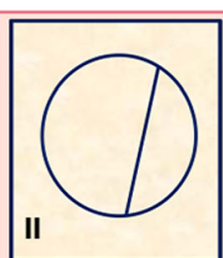

$0 \%$

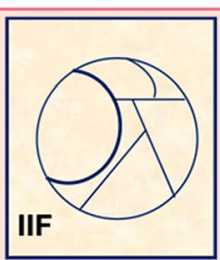

$5 \%$

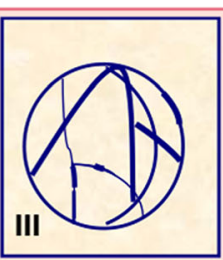

$50-70 \%$

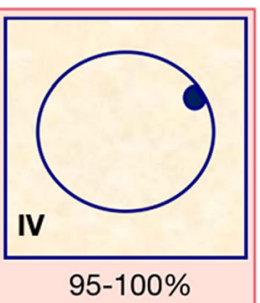

$95-100 \%$

Fig. 14 Schematization of Bosniak's classification for cystic renal masses and associated malignancy rate. Bosniak I: hairline-thin wall without septa, calcifications, or solid components; malignancy rate of 0\%. Bosniak II: few hairline-thin septa, fine calcifications in a short segment of the wall, or slightly thickened calcification; malignancy rate of $0 \%$. Bosniak IIF: multiple hairline-thin septa, smooth minimal thickening of the wall or septa, and thick or nodular calcifications; malignancy rate of 5\%. Bosniak III: thickened irregular wall or septa with enhancement after the administration of contrast agent; malignancy rate of 50-70\%. Bosniak IV: soft tissue enhancing mass independent of the wall or septa; malignancy rate of 95-100\%. Remember that Bosniak I-II cysts do not need follow-up, Bosniak IIF cysts need follow-up, and surgery is indicated for Bosniak III-IV cysts 


\section{Complex renal cysts and active surveillance}

With the increasing incidental identification of solid SRMs, the identification of complex cystic renal masses has increased by 8 to $15 \%$ in renal cysts [49]. The complexity of renal cysts is classified using the Bosniak renal cyst classification system, which was first applied in CT and MR and more recently in CEUS $[13,16]$. The Bosniak classification or determination of renal cyst complexity was initially used to aid in differentiating nonsurgical (categories I, 2II, and IIF) from surgical lesions (categories III-IV) according to the category of malignancy probability (Fig. 14). According to the Bosniak classification system, a IIF cyst should be followed, while surgery is indicated for Bosniak III and IV cysts, despite the knowledge that $50 \%$ of Bosniak III cysts are benign.

Cystic RCCs (multilocular cystic RCC, cystic RCC, and $\mathrm{RCC}$ with cystic degeneration) are usually low-stage and low-grade tumors with an excellent prognosis [13, 50, 51]. In a recent series of IIF and III cysts undergoing AS, none showed local progression or metastatic disease, making it unclear whether Bosniak III warrants the aggressive surgical treatment that is currently recommended. Therefore, it may be possible to offer AS to patients with progressive Bosniak IIF or Bosniak III as an alternative to surgery in certain clinical scenarios similar to that of patients with SRMs [43].

The Bosniak IIF group included both less and more complex lesions (Fig. 15). In the former group, a followup of 1-2 years may be sufficient, while the latter group may require repeated imaging for at least 4 years [52]. More complex Bosniak IIF lesions that do not change within 2 years may be followed with another CT/MR 24 months later, and if no changes are observed, follow-up can thereafter be discontinued [43].

Recently, Bosniak III cysts have been classified as Bosniak IIIs and IIIn. Bosniak IIIs cysts only have enhanced thickened septations, and Bosniak IIIn cysts have thickened walls or septal enhancement and nodularity, demonstrating that only Bosniak IIIn cysts are associated with progression (Fig. 16) [53]. In addition, in a recent study, a mural or septal nodule was associated with malignancy, but septation thickness, wall thickness, and cyst size were not found to be determinants of malignancy [54].

AS of complex renal cysts differs from that of solid masses. Figure 17 shows a possible follow-up algorithm for these lesions. The size of complex renal cysts has no correlation with the incidence of RCC or tumor aggressiveness, with a recent study reporting that malignant cysts are smaller than benign cysts [55]. During the follow-up of cysts, changes in the internal architecture such as septa and wall thickening or nodularity are taken into account to demonstrate progression [43]. The indolent behavior of cystic malignancies suggests that delayed intervention
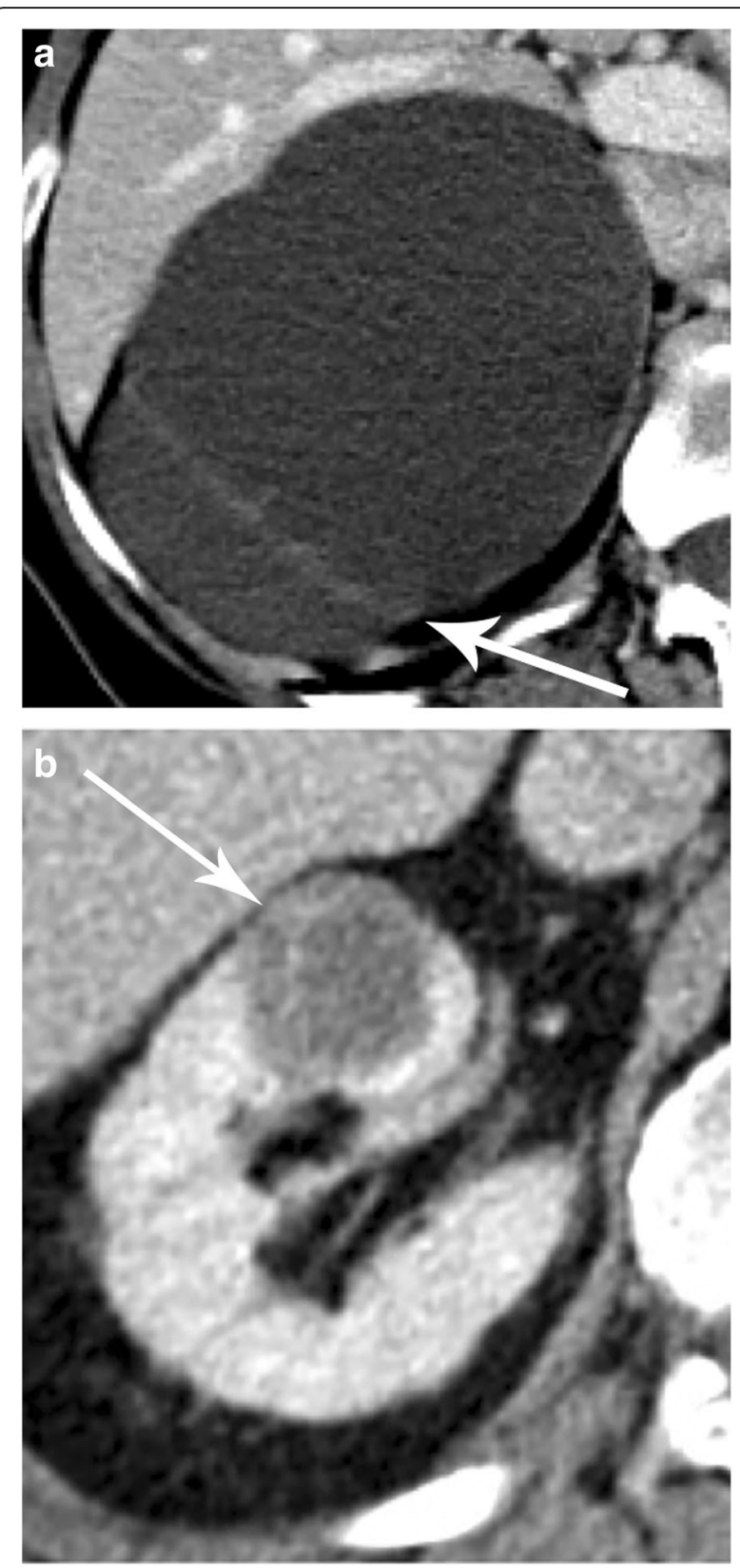

Fig. 15 Bosniak IIF, differentiation between low and more complex lesions. a Axial contrast-enhanced CT depicting a large cyst with a solitary thick septum. The cyst should be followed because the septum is thick, but suspicion of malignancy is very low (arrow). b Axial contrast-enhanced CT demonstrating a cyst with multiple septa. This complex appearance does not completely rule out a possible cystic tumor (arrow)

should be strongly considered when treating patients with cystic renal masses, even Bosniak IIIn and IV cysts in the same scenarios recommended in SRM guidelines.

However, Bosniak IV renal cysts can also be highly necrotic and aggressive solid renal neoplasms. There is limited experience with imaging surveillance of Bosniak IV renal lesions. In cases of AS of Bosniak IV tumors, if a 

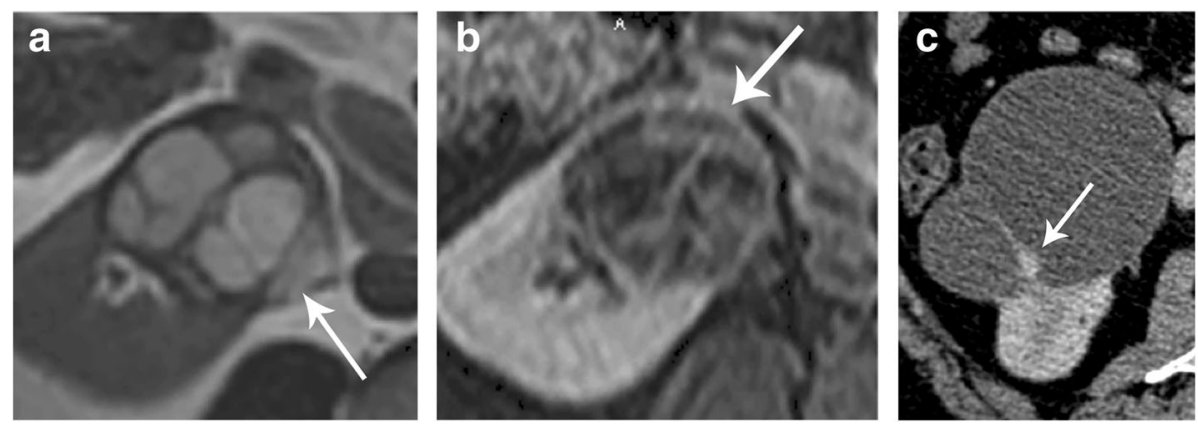

Fig. 16 Bosniak IIIs ( $\mathbf{a}, \mathbf{b})$ and IIIn (c) lesions. a Axial T2-weighted MR showing a multiseptated cystic renal lesion (arrow) and (b) axial T1 postcontrast MR of the same lesion showing septal enhancement (arrow) consistent with a Bosniak Ills cyst. c Axial contrast-enhanced CT of a cystic renal mass with septae nodularity (arrow) considered to be a Bosniak IIIn cyst

solid nodular septum or nodular wall cannot consistently be found in order to correctly follow-up in terms of progression, we suggest managing it as a small renal mass (Fig. 7) and not as a cystic Bosniak IV in terms of progression. This means that in these cases, the correct follow-up procedure to assess progression is by checking the increase in diameter of the lesions [56].

Recent studies have demonstrated the high accuracy of CEUS in the characterization of baseline complex cysts [57]. In the study of Quaia et al., CEUS performed better than CT in the diagnosis of malignancy in complex cystic renal masses, with a similar diagnostic reliability between CEUS and CT [28]. CEUS can also be used instead of CT in the follow-up of Bosniak IIF cysts to detect any morphologic changes considered as progressions such as septa thickening, the appearance of a solid nodule, or contrastenhanced modifications indicative of disease progression with the additional benefits of a reduction in costs and radiation exposure. CEUS helps to demonstrate the enhancement of hypovascular nodularities of cysts, which are not well demonstrated by CT or US (Fig. 18). CEUS is also useful in hemorrhagic cysts diagnosed by CT or MR, classified as Bosniak IIF if bigger than $3 \mathrm{~cm}$; if CEUS reclassifies these cases as Bosniak I-II, follow-up is not required (Fig. 19).

Historically, a percutaneous biopsy was not recommended in complex renal cysts because of the high rates of false-negative results, due to cyst septations; however, recent studies have described a better diagnostic yield [31, 58-61]. Nodular areas found inside the cysts should always be included in the RTB (Fig. 20).

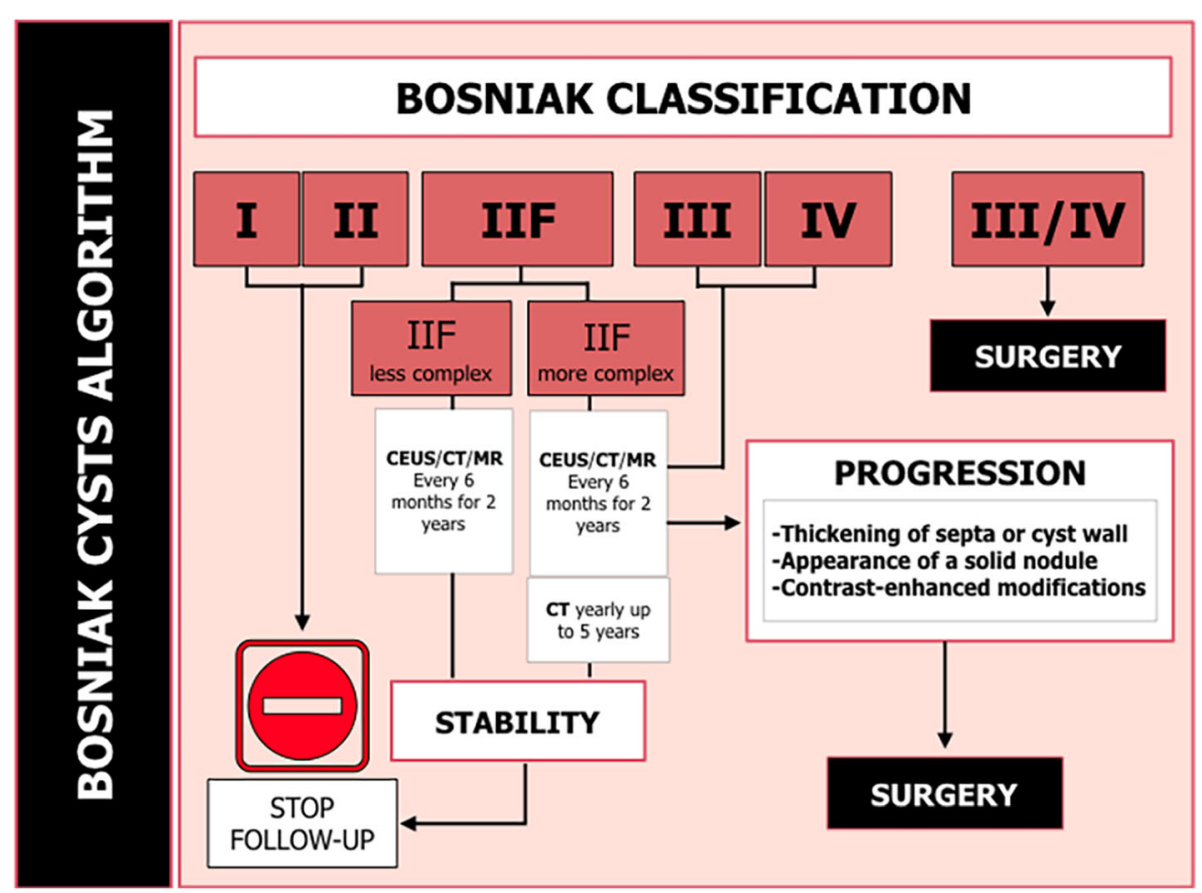

Fig. 17 Suggested Bosniak cyst classification management algorithm 

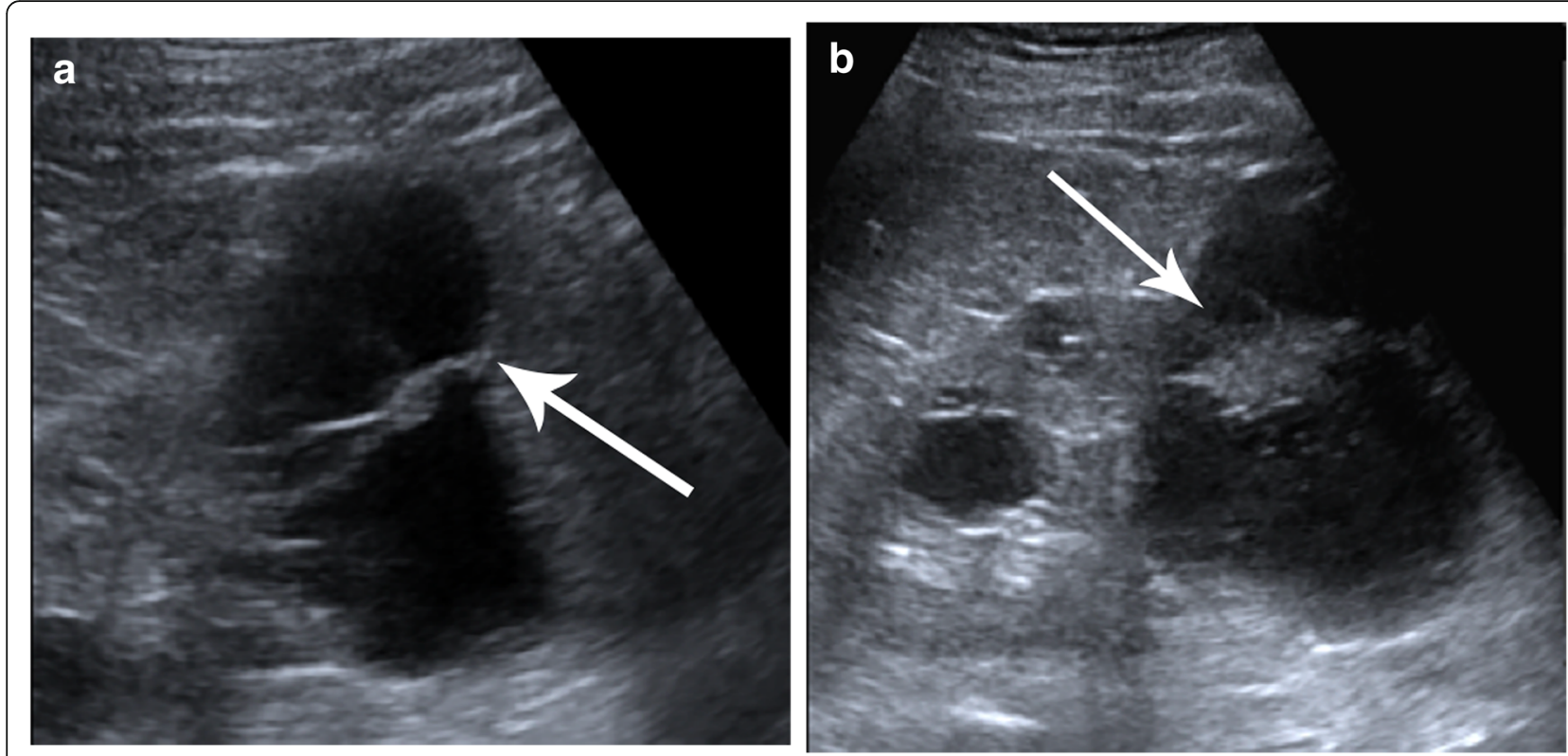

Fig. 18 Cystic Bosniak IIF renal mass (arrows) presenting growth over time and showing malignant features with an occurrence rate of 5\%. a Unenhanced US showing a cystic renal lesion with thickened septa. b Unenhanced US of the same lesion 1 year later showing increasing nodularity in the previously thickened septa, consistent with progression

\section{Multifocal small renal masses and active surveillance}

It is important to clarify the meaning of multifocality. It is defined as the presence of more than one tumor, which can be unilateral or bilateral in SRMs. Multifocal SRMs can be synchronic or metachronous and are considered as synchronous if appearing within less than 6 months $[62,63]$.

It is more difficult to establish AS protocols for patients with multifocal SRMs than for patients with solitary SRMs. Indeed, there is no consensus in this regard in urological guidelines, and there is scarce literature about the clinical behavior of these masses, with only short series having been evaluated [63-66]. However, there is a real increase in the prevalence of multifocal renal tumors [67].

The presence of multifocal renal tumors is not unusual, and according to histological series after nephrectomy, they can appear in approximately $25 \%$ of patients with RCC $[68,69]$. Bilateral renal tumors have been observed in $90 \%$ of patients with multifocal tumors. The most frequent histological RCC variant associated with a multifocality is the papillary subtype, but any histologic RCC can be multifocal [62]. Multifocal renal tumors can be sporadic or associated with genetic syndromes. In patients with multifocal sporadic tumors, the recommendation of AS is the same as in single tumors. The linear
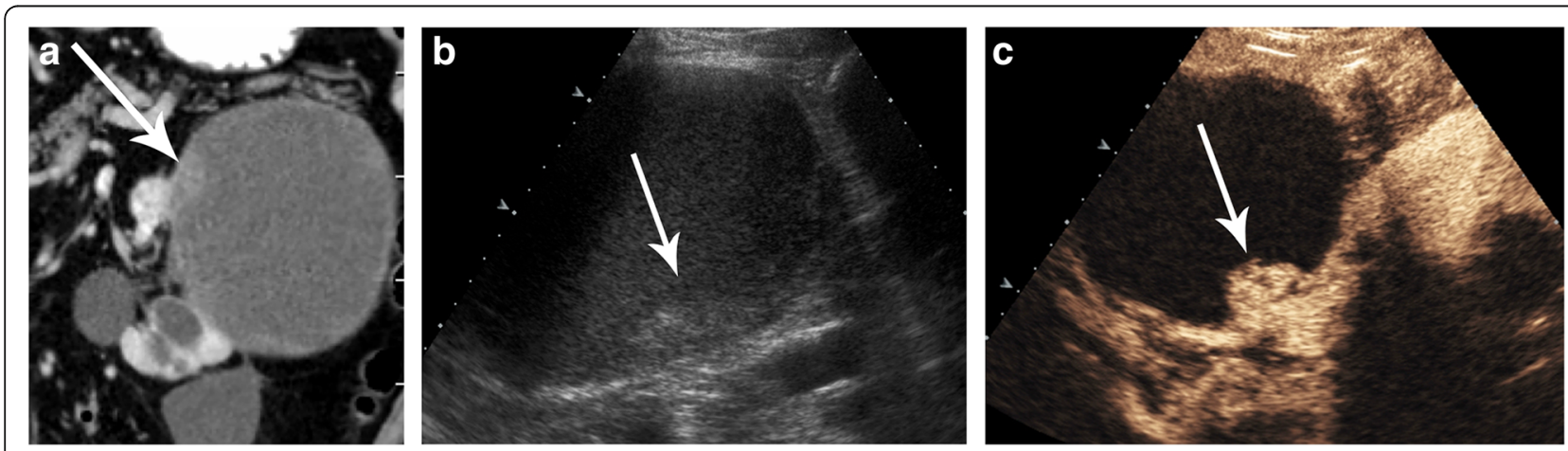

Fig. 19 Contrast-enhanced US image showing a cystic renal lesion in the wall of the left kidney suspected of being a solid lesion. a Coronal contrast-enhanced CT showing a cystic renal mass with a hard-to-define image in its wall (arrow). c Unenhanced and (d) contrast-enhanced US clearly depicting enhancement on this solid nodule (arrows) in the cyst wall, leading to the lesion being defined and classified as a Bosniak II lesion 

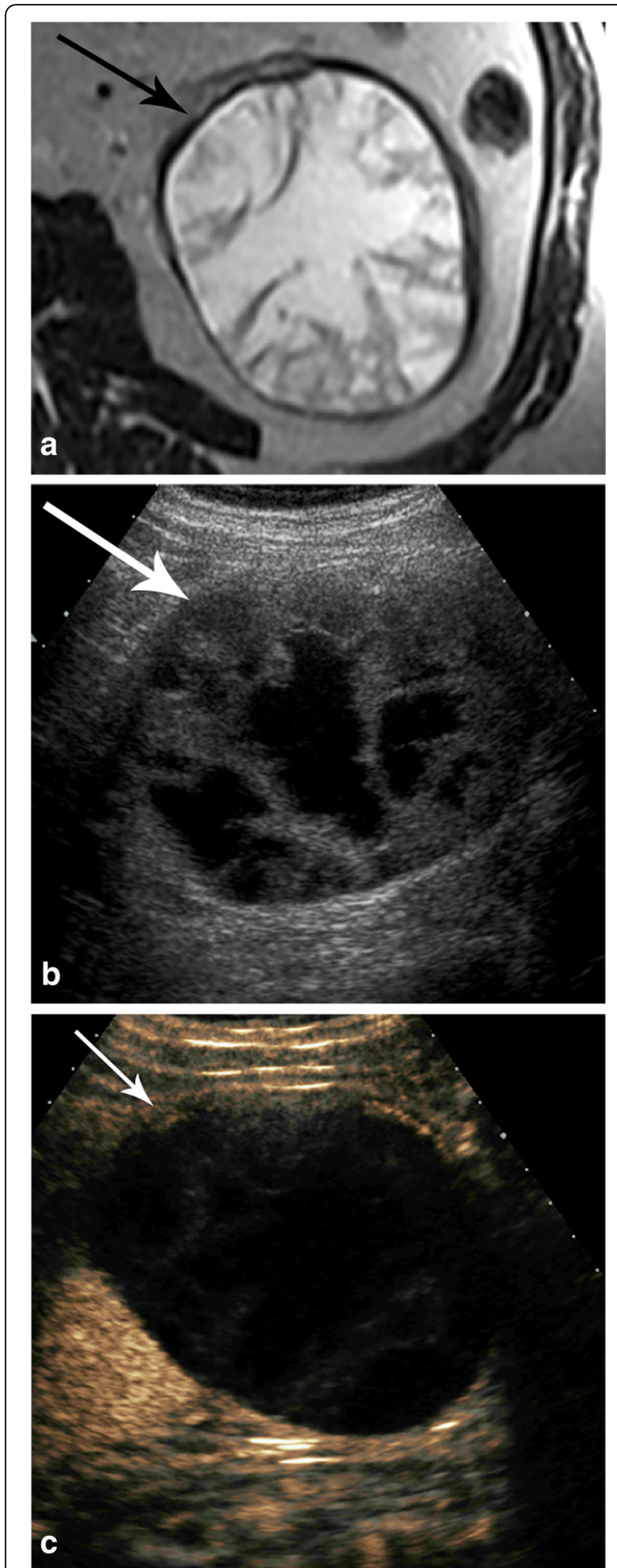

Fig. 20 Image suspected of being a complex hemorrhagic cyst larger than $3 \mathrm{~cm}$ in size, which was classified as Bosniak IIF, and then later reclassified as a Bosniak II cyst by contrast-enhanced US. a Axial T2 MR showing a complex renal cyst with thick septa (arrow). b Unenhanced US of the same lesion showing cystic component and echogenic material within the cyst (arrow). c Contrast-enhanced US showing the absence of enhancement of septa (arrow). The lesion was reclassified as a Bosniak I simple cyst not requiring follow-up

GR of all the SRMs is measured and calculated in routine clinical practice.

The management of multifocal renal tumors with genetic predisposition is even more challenging, and at present, there is no urological or oncological consensus in this regard. Approximately 5 to $8 \%$ of renal cancers have a hereditary component, and some studies have reported that in up to $58 \%$ of these tumors, family genetics plays a significant role [70].

In patients with hereditary syndromes, RCC appears at a younger age and have a greater propensity to develop synchronic and metachronous renal tumors. As a result, the likelihood of these patients requiring multiple surgical kidney procedures should be taken into account [71]. It is important to diagnose these syndromes early. The most frequent syndromes associated with multiple renal tumors are Von HippelLindau (VHL), hereditary papillary renal cell carcinoma (HPRC), tuberous sclerosis complex (TSC), hereditary leiomyomatosis RCC (HLRCC), succinate dehydrogenase B deficiency (SDHB), and Cowden syndromes. The more recently described syndromes are associated with genetic alterations in BRCA1associated protein-1 (BAP1) or microphthalmiaassociated transcription factor (MITF). In patients with multifocal sporadic or hereditary SRMs, RTB is always recommended, if technically possible [63]. The ideal follow-up includes size measurement and linear GR calculation of all tumors, but this can be technically challenging and time-consuming. In the presence of multiple multifocal renal masses, we recommend measuring only SMRs larger than $2 \mathrm{~cm}$ or those that seem to have more rapid growth (Fig. 21).

In patients with multifocal SRMs, the main objectives of management are preserving renal function, avoiding surgical morbimortality, achieving optimal oncological control, and providing long-term cancer recurrence-free survival. AS is the treatment of choice in sporadic multifocal and some hereditary SRMs. In classical hereditary syndromes (VHL, HPRC, and $\mathrm{BHD}), \mathrm{AS}$ is recommended until the tumor reaches 3 $\mathrm{cm}$. In HLRCC and SDHB, the risk of metastatic disease in smaller tumors is high. Therefore, surgery is always recommended. There is no consensus on new syndromes, and therefore, immediate surgery after 


\section{MANAGEMENT OF MULTIFOCAL RENAL MASSES}

\begin{tabular}{|c|c|c|}
\hline SYNDROME & ASSOCIATED RENAL TUMORS & FOLLOW-UP PROTOCOL \\
\hline $\begin{array}{l}\text { Von Hippel Lindau } \\
\text { Syndrome }\end{array}$ & $\begin{array}{l}\text { Simple or complex renal cysts } \\
\text { Clear Cell RCC }\end{array}$ & Up to $3 \mathbf{c m}$ \\
\hline $\begin{array}{l}\text { Hereditary Papillary Renal Cell } \\
\text { Carcinoma }\end{array}$ & Papillary type I RCC & Up to $3 \mathbf{c m}$ \\
\hline $\begin{array}{l}\text { Birt-Hogg-Dubé } \\
\text { Syndrome }\end{array}$ & $\begin{array}{c}\text { Clear Cell Carcinoma } \\
\text { Chromophobe Renal Cell Carcinoma } \\
\text { Oncocytoma }\end{array}$ & Up to $3 \mathbf{c m}$ \\
\hline Tuberous Sclerosis Complex & $\begin{array}{l}\text { Simple or complex renal cysts } \\
\text { Wide range of RCC } \\
\text { Angiomyolipomas }\end{array}$ & Up to $3 \mathbf{c m}$ \\
\hline $\begin{array}{l}\text { Hereditary Leiomyomatosis Renal } \\
\text { Cell Carcinoma (Reed's Syndrome) }\end{array}$ & Type II papillary Renal Cell Carcinoma & $\begin{array}{l}\text { Surgery is always } \\
\text { recommended }\end{array}$ \\
\hline $\begin{array}{c}\text { Succinate Dehydrogenase B } \\
\text { Deficiency }\end{array}$ & Clear Cell RCC & $\begin{array}{l}\text { Surgery is always } \\
\text { recommended }\end{array}$ \\
\hline $\begin{array}{l}\text { BRCA } 1 \text { associated protein-1 (BAP1) } \\
\text { Renal Cell Carcinoma }\end{array}$ & Clear Cell RCC & $\begin{array}{l}\text { Surgery is always } \\
\text { recommended }\end{array}$ \\
\hline $\begin{array}{l}\text { MITF predisposed } \\
\text { Renal Cell Carcinoma }\end{array}$ & Uncertain histology & $\begin{array}{l}\text { Surgery is always } \\
\text { recommended }\end{array}$ \\
\hline
\end{tabular}

Fig. 21 Multifocal small renal masses (SRM), genetic syndromes classification, type of associated renal tumors, and suggested follow-up by active surveillance (AS)

diagnosis is also recommended, even in very small tumors [72, 73].

\section{Conclusion}

AS is effective in the treatment of SRMs. It is mandatory for radiologists to know how to most adequately manage AS in SRMs in order to achieve the most optimal results. Complicated renal cysts and multifocal renal masses need a specific approach.

\section{Abbreviations}

AS: Active surveillance; ASCO: American Society of Clinical Oncology;

AUA: American Urology Association; CEUS: Contrast-enhanced ultrasound; GR: Growth rate; HLRCC: Hereditary leiomyomatosis renal cell carcinoma; HPRC: Hereditary papillary renal cell carcinoma; NCCN: National Comprehensive Cancer Network; RCC: Renal cell carcinoma; RTB: Renal tumor biopsy; SDHB: Succinate dehydrogenase B; SRM: Small renal mass;

TSC: Tuberous sclerosis complex; TSTC: Too small to be characterized renal masses; VHL: Von Hippel-Lindau; WW: Watchful waiting
Funding

Not applicable

Availability of data and materials Not applicable

Ethics approval and consent to participate Not applicable

Consent for publication

Not applicable

Competing interests

The authors declare that they have no competing interests.

\section{Author details}

${ }^{1}$ Radiology Department, CDIC, Hospital Clínic de Barcelona, CNillaroel no. 170, 08036 Barcelona, Spain. ${ }^{2}$ Urology Department, ICNU, Hospital Clínic de Barcelona, CNillaroel no. 170, 08036 Barcelona, Spain.

Received: 25 September 2019 Accepted: 2 March 2020

Published online: 05 May 2020

References

1. Gill IS, Aron M, DA Gervais MJ (2010) Small renal mass. N Engl J Med 362(7): 624-634 
2. Finelli A, Ismaila N, Bro B et al (2017) Management of small renal masses: American Society of Clinical Oncology clinical practice guideline. J Clin Oncol. 35(6):668-680

3. Ward RD, Tanaka H, Campbell SC, Remer EM (2018) 2017 AUA renal mass and localized renal cancer guidelines: imaging implications. Radiographics 38(7):2021-2033 Available from: http://pubs.rsna.org/doi/10.1148/rg.20181 80127

4. Cadeddu JA, Chang A, Clark PE et al (2017) American Urological Association (AUA). Renal mass and localized renal cancer: AUA guideline American Urological Association (AUA). Am Urol Assoc:1-49 Available from: http:// auanet.org/guidelines/renal-mass-and-localized-renal-cancer-new-(2017)

5. Chawla SN, Crispen PL, Hanlon AL, Greenberg RE, Chen DYT, Uzzo RG (2006) The natural history of observed enhancing renal masses: meta-analysis and review of the world literature. J Urol. 175(2):425-431

6. Volpe A, Panzarella T, Rendon RA, Haider MA, Kondylis Fl, Jewett MAS (2004) The natural history of incidentally detected small renal masses. Cancer. 100(4):738-745

7. Greenberg RE, Crispen PL, Viterbo R, Uzzo RG, Fox EB, Chen DYT (2008) Delayed intervention of sporadic renal masses undergoing active surveillance. Cancer. 112(5):1051-1057

8. Touma N, Hosier G, Di Lena M et al (2018) Growth rates and outcomes of observed large renal masses. Can Urol Assoc J 13(8).

9. Hora M, Powles T, Mulders P, Dabestani S, Staehler M, Canfield S et al (2015) EAU guidelines on renal cell carcinoma: 2014 update. Eur Urol. 67(5):913924 Available from: https://doi.org/10.1016/j.eururo.2015.01.005

10. Gervais DA, Giambarresi L, Lane BR et al (2017) Renal mass and localized renal cancer: AUA guideline. J Urol. 198(3):520-529 Available from: https:// doi.org/10.1016/j.juro.2017.04.100

11. Jewett MAS, Richard PO, Finelli A (2015) Management of small renal mass: an opportunity to address a growing problem in early stage kidney cancer. Eur Urol. 68(3):416-417 Available from: https://doi.org/10.1016/j.eururo.2015. 05.011

12. Gordetsky J, Eich M, Garapati M, Rodriguez C, Rais-bahrami S (2019) Defining a small renal mass. Urology 123:157-166 Available from: https:// doi.org/10.1016/j.urology.2018.09.017

13. Bosniak MA (1986) The current radiological approach to renal cyst. Radiology 158(1):1-10

14. Herts BR, Silverman SG, Hindman NM et al (2018) Management of the incidental renal mass on CT: a white paper of the ACR Incidental Findings Committee. J Am Coll Radiol. 15(2):264-273 Available from: https://doi.org/ 10.1016/j.jacr.2017.04.028

15. Bertolotto M, Cicero C, Perrone R, Degrassi F, Cacciato F, Cova MA (2015) Renal masses with equivocal enhancement at $\mathrm{CT}$ : characterization with contrast-enhanced ultrasound. AJR Am J Roentgenol. 204(5):W557-W565

16. Nicolau C, Bunesch L, Sebastia C (2011) Renal complex cysts in adults: contrast-enhanced ultrasound. Abdom Imaging. 36(6):742-752

17. Nicolau C, Buñesch L, Paño B et al (2015) Prospective evaluation of CT indeterminate renal masses using US and contrast-enhanced ultrasound. Abdom Imaging. 40(3):542-551

18. Egbert ND, Caoili EM, Cohan $\mathrm{RH}$, Davenport MS, Francis IR, Ellis JH et al (2013) Differentiation of papillary renal cell carcinoma subtypes on CT and MRI. AJR Am J Roentgenol 201(2):347-355

19. Williamson SR, Taneja K, Cheng L (2019) Renal cell carcinoma staging: pitfalls, challenges, and updates. Histopathology. 74(1):18-30

20. Hu EM, Zhang A, Silverman SG et al (2018) Multi-institutional analysis of C and MRI reports evaluating indeterminate renal masses: comparison to a national survey investigating desired report elements. Abdom Radiol (NY) Available from:1-10 https://doi.org/10.1007/s00261-018-1609-x

21. Kay FU, Pedrosa I (2018) Imaging of solid renal masses. Urol Clin North Am 45(3):311-330 Available from: https://doi.org/10.1016/j.ucl.2018.03.013

22. Lopes Vendrami C, Parada Villavicencio C, DeJulio TJ et al (2017) Differentiation of solid renal tumors with multiparametric MR imaging. Radiographics 37(7):2026-2042 Available from: http://pubs.rsna.org/doi/1 $0.1148 /$ rg.2017170039

23. Marconi L, Powles T, Volpe A et al (2015) Systematic review and meta-analysis of diagnostic accuracy of percutaneous renal tumour biopsy. Eur Urol. 69(4): 660-673 Available from: https://doi.org/10.1016/j.eururo.2015.07.072

24. Bhindi B, Thompson $\mathrm{RH}$, Lohse $\mathrm{CM}$ et al (2018) The probability of aggressive versus indolent histology based on renal tumor size: implications for surveillance and treatment. Eur Urol 74(4):489-497 Available from: https://doi. org/10.1016/j.eururo.2018.06.003
25. Dabestani S, Beisland C, Stewart GD et al (2019). Long-term outcomes of follow-up for initially localised clear cell renal cell carcinoma: RECUR Database Analysis. Eur Urol Focus 5(5):857-866.

26. Sim SH, Messenger MP, Gregory WM et al (2012) Prognostic utility of preoperative circulating osteopontin, carbonic anhydrase IX and CRP in renal cell carcinoma. Br J Cancer 107(7):1131-1137 Available from: https://doi.org/ 10.1038/bjc.2012.360

27. Paterson C, Ghaemi J, Alashkham A et al (2018) Diagnostic accuracy of image-guided biopsies in small $(<4 \mathrm{~cm})$ renal masses with implications for active surveillance: a systematic review of the evidence. Br J Radiol 91(1090): 20170761

28. Turajlic S, Xu H, Litchfield K et al (2018) Deterministic evolutionary trajectories influence primary tumor growth: TRACERx Renal. Cell 173(3): 595-610.e11

29. Ueno D, Xie Z, Boeke M et al (2018) Genomic heterogeneity and the small renal mass. Clin Cancer Res. 24(17):4137-4144

30. Richard PO, Jewett MAS, Bhatt JR et al (2015) Renal tumor biopsy for small renal masses: a single-center 13-year experience. Eur Urol. 68(6):1007-1013 Available from: https://doi.org/10.1016/j.eururo.2015.04.004

31. Volpe A, Finelli A, Gill IS et al (2012) Rationale for percutaneous biopsy and histologic characterisation of renal tumours. Eur Urol. 62(3):491-504

32. Motzer RJ, Jonasch E, Agarwal N et al (2017) Kidney cancer, version 2.2017: clinical practice quidelines in oncology. J Natl Compr Cancer Netw. 15(6):804-834

33. Khan I, Beksac AT, Paulucci DJ et al (2017) Differences in renal tumor size measurements for computed tomography versus magnetic resonance imaging: implications for patients on active surveillance. J Laparoendosc Adv Surg Tech A 27(12):1275-1278 Available from: http://online.liebertpub. com/doi/10.1089/lap.2017.0234

34. Choi SM, Choi DK, Kim TH et al (2015). A comparison of radiologic tumor volume and pathologic tumor volume in renal cell carcinoma (RCC). PLoS One. 10(3):1-10

35. Kurta JM, Thompson RH, Kundu S et al (2009) Contemporary imaging of patients with a renal mass: does size on computed tomography equal pathological size? BJU Int. 103(1):24-27

36. Chen W, Wang L, Yang Q, Liu B, Sun Y (2013) Comparison of radiographic and pathologic sizes of renal tumors. Int Braz J Urol. 39(2):189-194

37. Nayyar M, Cheng P, Desai B et al (2016) Active surveillance of small renal masses: a review on the role of imaging with a focus on growth rate. $J$ Comput Assist Tomogr. 40(4):517-523

38. Dorin R, Jackson M, Cusano A et al (2014) Active surveillance of renal masses: an analysis of growth kinetics and clinical outcomes stratified by radiological characteristics at diagnosis. Int Braz J Urol. 40(5):627-636

39. Dababneh $H$, Brunocilla E, Bianchi L et al (2014) Small renal masses managed with active surveillance: predictors of tumor growth rate after long-term follow-up. Clin Genitourin Cancer 13(2):e87-e92 Available from: https://doi.org/10.1016/j.clgc.2014.08.006

40. Mehrazin R, Smaldone MC, Kutikov A et al (2014) Growth kinetics and shortterm outcomes of CT1b and CT2 renal masses under active surveillance. J Urol. 192(3):659-664 Available from: https://doi.org/10.1016/j.juro.2014.03.038

41. Organ M, Jewett M, Basiuk J et al (2014) Growth kinetics of small renal masses: a prospective analysis from the renal cell carcinoma consortium of Canada. Can Urol Assoc J 8(1-2):24-27

42. Smaldone MC, Kutikov A, Egleston BL et al (2012) Small renal masses progressing to metastases under active surveillance: a systematic review and pooled analysis. Cancer. 118(4):997-1006

43. Weibl P, Klatte T, Kollarik B et al (2011) Interpersonal variability and present diagnostic dilemmas in Bosniak classification system. Scand J Urol Nephrol 45(4):239-244 Available from: http://www.tandfonline.com/doi/full/10.3109/ 00365599.2011 .562233

44. Liaw CW, Winoker JS, Mehrazin R (2018) Imaging protocols for active surveillance in renal cell carcinoma. Curr Urol Rep. 19(10):1-7

45. Uzosike AC, Patel HD, Alam R et al (2018) Growth kinetics of small renal masses on active surveillance: variability and results from the DISSRM Registry. J Urol 199(3):641-648 Available from: https://doi.org/10.1016/j.juro. 2017.09.087

46. Crispen PL, Viterbo R, Boorjian SA, Greenberg RE, Chen DYT, Uzzo RG (2009) Natural history, growth kinetics, and outcomes of untreated clinically localized renal tumors under active surveillance. Cancer. 115(13):2844-2852

47. Punnen S, Haider MA, Lockwood G, Moulding F, O'Malley ME, Jewett MAS (2006) Variability in size measurement of renal masses smaller than $4 \mathrm{~cm}$ on computerized tomography. J Urol. 176(6):2386-2390 
48. Mucksavage P, Ramchandani P, Malkowicz SB, Guzzo TJ (2012) Is ultrasound imaging inferior to computed tomography or magnetic resonance imaging in evaluating renal mass size? Urology. 79(1):28-31

49. Chandrasekar T, Ahmad AE, Fadaak K et al (2018) Natural history of complex renal cysts: clinical evidence supporting active surveillance. J Urol 199(3): 633-640 Available from: https://doi.org/10.1016/j.juro.2017.09.078

50. Siegel RL, Miller KD, Jemal A (2019) Cancer statistics, 2019. CA Cancer J Clin 69(1):7-34 Available from: http://www.ncbi.nlm.nih.gov/pubmed/30620402

51. Schoots IG, Zaccai K, Hunink MG, Verhagen PCMS (2017) Bosniak classification for complex renal cysts reevaluated: a systematic review. J Urol. 198(1):12-21 Available from: https://doi.org/10.1016/j.juro.2016.09.160

52. Bosniak MA (2012) The Bosniak renal cyst classification: 25 years later. Radiology. 262(3):781-785

53. Pruthi DK, Liu Q, Kirkpatrick IDC, Gelfond J, Drachenberg DE (2018) Longterm surveillance of complex cystic renal masses and heterogeneity of Bosniak 3 lesions. J Urol 200(6):1192-1199 Available from: https://doi.org/10. 1016/j.juro.2018.07.063

54. Reese AC, Johnson PT, Gorin MA et al (2014) Pathological characteristics and radiographic correlates of complex renal cysts. Urol Oncol Semin Orig Investig 32(7):1010-1016 Available from: https://doi.org/10.1016/j.urolonc. 2014.02.022

55. Weibl P, Hora M, Kollarik B, Shariat SF, Klatte T (2015) Management, pathology and outcomes of Bosniak category IIF and III cystic renal lesions. World J Urol. 33(3):295-300

56. Smith AD, Allen BC, Carson JD et al (2015) Outcomes and complications related to the management of Bosniak cystic renal lesions. AJR Am J Roentgenol 204(5):550-556

57. Quaia E, Bertolotto M, Cioffi V et al (2008) Comparison of contrast-enhanced sonography with unenhanced sonography and contrast-enhanced $C T$ in the diagnosis of malignancy in complex cystic renal masses. AJR Am J Roentgenol. 191(4):1239-1249

58. Braunagel M, Graser A, Reiser M, Notohamiprodjo M (2014) The role of functional imaging in the era of targeted therapy of renal cell carcinoma. World J Urol. 32(1):47-58

59. Hora M, Hes O, Michal M et al (2005) Extensively cystic renal neoplasms in adults (Bosniak Classification II or III) - possible "common" histological diagnoses: multilocular cystic renal cell carcinoma, cystic nephroma, and mixed epithelial and stromal tumor of the kidney. Int Urol Nephrol. 37(4): 743-750

60. Hora M, Ürge T, Eret $V$ et al (2011) Tubulocystic renal carcinoma: a clinical perspective. World J Urol. 29(3):349-354

61. Siracusano S, Bertolotto M, Ciciliato S, Valentino M, Liguori G, Visalli F (2011) The current role of contrast-enhanced ultrasound (CEUS) imaging in the evaluation of renal pathology. World J Urol. 29(5):633-638

62. Shuch B, Singer EA, Bratslavsky G (2012) The surgical approach to multifocal renal cancers: hereditary syndromes, ipsilateral multifocality, and bilateral tumors. Urol Clin North Am. 39(2):133-148

63. Sheikh NA, Khan MH, Pillai S, Lang S, Nabi G (2018) Outcomes of synchronous and metachronous bilateral small renal masses $(<4 \mathrm{~cm})$ : a population-based cohort study. Int Urol Nephrol. 50(4):657-663

64. Hu X-Y, Xu L, Guo J-M, Wang H (2017) Surgical strategy of bilateral synchronous sporadic renal cell carcinoma-experience of a Chinese university hospital. World J Surg Oncol. 15(1):53

65. Berczi C, Thomas B, Bacso Z, Flasko T (2016) Bilateral renal cancers: oncological and functional outcomes. Int Urol Nephrol. 48(10):1617-1622

66. Wells GM, Schroth W, Brauch H, Ross EA (2009) Bilateral renal-cell carcinoma associated with an acquired $\mathrm{VHL}$ mutation and long-term trichloroethylene exposure. Clin Nephrol. 71(6):708-713

67. Hollingsworth JM, Miller DC, Daignault S, Hollenbeck BK (2006) Rising incidence of small renal masses: a need to reassess treatment effect. J Natl Cancer Inst. 98(18):1331-1334

68. Whang M, O'Toole K, Bixon R et al (1995) The incidence of multifocal renal cell carcinoma in patients who are candidates for partial nephrectomy. J Urol. 154(3):968-970 discussion 970-1

69. Cheng WS, Farrow GM, Zincke H (1991) The incidence of multicentricity in renal cell carcinoma. J Urol. 146(5):1221-1223

70. Gudbjartsson T, Jónasdóttir TJ, Thoroddsen Á et al (2002) A populationbased familial aggregation analysis indicates genetic contribution in a majority of renal cell carcinomas. Int J Cancer. 100(4):476-479

71. Bratslavsky G, Linehan WM (2010) Long-term management of bilateral, multifocal, recurrent renal carcinoma. Nat Rev Urol. 7(5):267-275
72. Walther MM, Choyke PL, Glenn G et al (1999) Renal cancer in families with hereditary renal cancer: prospective analysis of a tumor size threshold for renal parenchymal sparing surgery. J Urol. 161(5):1475-1479

73. Herring JC, Enquist EG, Chernoff A, Linehan WM, Choyke PL, Walther MM (2001) Parenchymal sparing surgery in patients with hereditary renal cell carcinoma: 10-year experience. J Urol. 165(3):777-781

\section{Publisher's Note}

Springer Nature remains neutral with regard to jurisdictional claims in published maps and institutional affiliations.

\section{Submit your manuscript to a SpringerOpen ${ }^{\circ}$ journal and benefit from:}

- Convenient online submission

- Rigorous peer review

- Open access: articles freely available online

- High visibility within the field

- Retaining the copyright to your article

Submit your next manuscript at $\boldsymbol{\nabla}$ springeropen.com 